Published in final edited form as:

ACS Nano. 2018 June 26; 12(6): 5834-5847. doi:10.1021/acsnano.8b01806.

\title{
C1q-Mediated Complement Activation and C3 Opsonization Trigger Recognition of Stealth Poly(2-methyl-2-oxazoline)-Coated Silica Nanoparticles by Human Phagocytes
}

\author{
Regina Tavano ${ }^{\dagger}$, Luca Gabrielli ${ }^{\ddagger}$, Elisa Lubian ${ }^{\ddagger}$, Chiara Fedeli $^{\dagger, \nabla}$, Silvia Visentin ${ }^{\dagger,}$, , Patrizia \\ Polverino De Laureto ${ }^{\S}$, Giorgio Arrigoni ${ }^{\dagger}$, Alessandra Geffner-Smith ${ }^{\dagger}$, Fangfang Chen ${ }^{\|, \perp}$, \\ Dmitri Simberg", Giulia Morgese ${ }^{\#}$, Edmondo M. Benetti\#, Linping Wuף, ${ }^{\mathbb{A}}$, Seyed Moein \\ Moghimi ${ }^{*}, \|, \Delta, \triangleleft$, Fabrizio Mancin ${ }^{\ddagger}$, and Emanuele Papini ${ }^{*}, \dagger$
}

†Department of Biomedical Sciences, University of Padua, Padua 35121, Italy $¥$ Department of Chemical Sciences, University of Padua, Padua 35121, Italy §Department of Pharmaceutical Sciences, University of Padua, Padua 35121, Italy "Translational Bio-Nanosciences Laboratory and Colorado Center for Nanomedicine and Nanosafety, The Skaggs School of Pharmacy and Pharmaceutical Sciences, Department of Pharmaceutical Sciences, University of Colorado Denver, Anschutz Medical Campus, 1250 East Mountview Boulevard, Aurora, Colorado 80045, United States ${ }^{\perp}$ Department of Gastrointestinal Surgery, China-Japan Union Hospital, Jilin University, 126 Xiantai Street, Changchun, Jilin 130033, China \#Department of Materials, ETH, Zurich $\mathrm{CH}-8093$, Switzerland "Guangzhou Institute of Biomedicine and Health, Chinese Academy of Sciences, Guangzhou 510530, China ${ }^{\triangle}$ School of Pharmacy, Newcastle University, Newcastle upon Tyne NE1 7RU, United Kingdom ^Institute of Cellular Medicine, Newcastle University, Framlington Place, Newcastle upon Tyne NE2 4HH, United Kingdom

\footnotetext{
*Corresponding Authors: seyed.moghimi@ncl.ac.uk.; emanuele.papini@unipd.it.

${ }^{\nabla}$ Institut de microbiologie, CHUV, Rue du Bugnon 48, CH-1011 Lausanne, Switzerland.

'School of Biological Science, College of Science and Engineering, University of Edinburgh, Edinburgh EH9 3BF, United Kingdom. Author Contributions

R.T., L.G., E.L., C.F., S.V., P.P.L., G.A., A.G.-S., F.C., G.M., E.M.B., and L.W. did experiments. All coauthors discussed and analyzed data. F.M., E.P., D.S., and S.M.M. wrote the paper with contribution from all coauthors.

Supporting Information

The Supporting Information is available free of charge on the ACS Publications website at DOI: 10.1021/acsnano.8b01806.

NP synthesis, additional physicochemical characterization; raw shot-gun data of protein and peptide identification in NP corona in HS (donor A) before and after treatment with chelating agents, iBAQ of identified polypeptides in NP corona, and SDS-PAGE gels after in situ digestion for different NP types; additional information on cytotoxicity, lectin pathway inhibition, antibody depletion of serum and C1q binding experiments; raw data on densitometry and further proteomics in selected sera; supplementary methods (PDF)

SI File 1: Donor A_Protein groups_MaxQuant (XLSX)

SI File 2: Donor A_Results MQ_Peptides (XLSX)

SI File 3: Shot gun elaborated data for effect of $\mathrm{Ca}^{2+}$ and $\mathrm{Mg}^{2+}$ on ORMOSIL-NP corona (XLSX)

SI File 4: PMOXA samples w or w-o EGTA-Mg or EDTA (XLSX)

SI File 5: Uncoated NPs_MS (XLSX)

SI File 6: Pegylated NPs_MS (XLSX)

SI File 7: PMOXA-coated NPs_MS (XLSX)

SI File 8: Donor D_Protein groups_MaxQuant (XLSX)

SI File 9: Donor D_Results MQ_Peptides (XLSX)

SI File 10: Donor F_Protein groups_MaxQuant (XLSX)

SI File 11: Donor F_Results MQ_Peptides (XLSX)

SI File 12: Shot gun elaborated data for NP corona composition estimation for three HS donors (XLSX)

The authors declare no competing financial interest.
} 


\section{Abstract}

Poly(2-methyl-2-oxazoline) (PMOXA) is an alternative promising polymer to poly(ethylene glycol) (PEG) for design and engineering of macrophage-evading nanoparticles (NPs). Although PMOXA-engineered NPs have shown comparable pharmacokinetics and in vivo performance to PEGylated stealth NPs in the murine model, its interaction with elements of the human innate immune system has not been studied. From a translational angle, we studied the interaction of fully characterized PMOXA-coated vinyltriethoxysilane-derived organically modified silica NPs (PMOXA-coated NPs) of approximately $100 \mathrm{~nm}$ in diameter with human complement system, blood leukocytes, and macrophages and compared their performance with PEGylated and uncoated NP counterparts. Through detailed immunological and proteomic profiling, we show that PMOXA-coated NPs extensively trigger complement activation in human sera exclusively through the classical pathway. Complement activation is initiated by the sensing molecule $\mathrm{C} 1 \mathrm{q}$, where $\mathrm{C} 1 \mathrm{q}$ binds with high affinity $\left(K_{\mathrm{d}}=11 \pm 1 \mathrm{nM}\right)$ to NP surfaces independent of immunoglobulin binding. C1q-mediated complement activation accelerates PMOXA opsonization with the third complement protein (C3) through the amplification loop of the alternative pathway. This promoted NP recognition by human blood leukocytes and monocyte-derived macrophages. The macrophage capture of PMOXA-coated NPs correlates with sera donor variability in complement activation and opsonization but not with other major corona proteins, including clusterin and a wide range of apolipoproteins. In contrast to these observations, PMOXA-coated NPs poorly activated the murine complement system and were marginally recognized by mouse macrophages. These studies provide important insights into compatibility of engineered NPs with elements of the human innate immune system for translational steps.

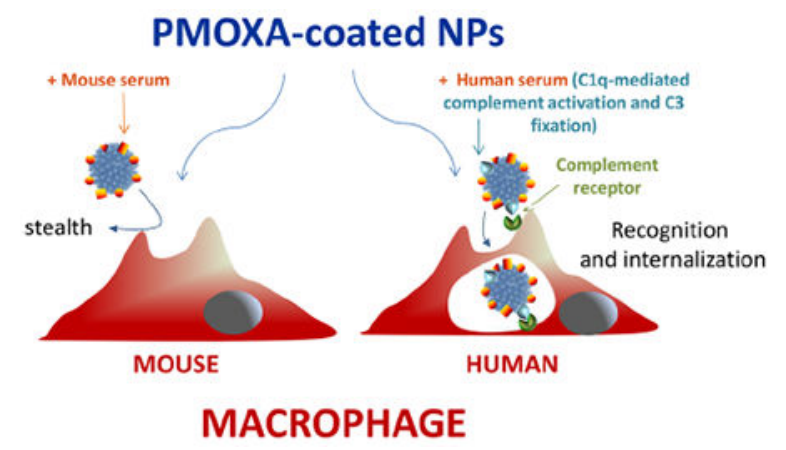

\section{Keywords}

C1q; C3; complement; human macrophages; polyoxazoline; stealth polymers

The interaction of intravenously injected nanoparticles (NPs) with the host blood proteins has long been suggested to modulate NP pharmacokinetics and their extent of clearance from systemic circulation by macrophages of the reticuloendothelial system (RES). ${ }^{1,2}$ The rapid clearance of therapeutic NPs by macrophages of the RES, however, could limit their delivery to target sites outside the liver and the spleen. ${ }^{1-4}$ Steric stabilization of NPs with long-chain hydrophilic polymers/copolymers has become a successful approach in minimizing protein binding and modulating NP pharmacokinetics and biodistribution. Among many engineered polymers, poly(ethylene glycol) (PEG) has widely been used for 
design and surface engineering of long-circulating NPs and vesicular drug carriers. ${ }^{5} \mathrm{~A}$ classic example is the regulatory-approved Doxil (a PEGylated liposomal formulation of doxorubicin) and its generic versions. ${ }^{6}$

Although PEGylation can successfully reduce adsorption of blood proteins to NPs, numerous studies have shown that opsonization of PEGylated NPs by the third protein of the complement system (C3) and its cleavage products $(\mathrm{C} 3 \mathrm{~b} / \mathrm{iC} 3 \mathrm{~b})$ may still occur, and this could lead to their efficient capture by human macrophages. ${ }^{7,8}$ It is also crucial to consider that some individuals may have antibodies that could recognize the PEG moiety of PEGylated nanopharmaceuticals. This may initiate macrophage recognition of PEGylated NPs through complement opsonization. ${ }^{9-13}$ Furthermore, PEG can undergo oxidative degradation, and this may increase its complement activation property. ${ }^{14}$ A number of animal and clinical studies have also indicated that PEGylated NPs may induce cardiopulmonary disturbances and distress. Earlier studies postulated that complement activation and subsequent release of $\mathrm{C} 3 \mathrm{a}$ and $\mathrm{C} 5 \mathrm{a}$ anaphylotoxins induced by PEGylated NPs may play a causal role in initiating such reactions. ${ }^{7,8,15,16}$ However, a recent study has demonstrated a transitional link between robust NP clearance from the blood by strategically placed macrophages in vasculature and adverse hemodynamic reactions independent of complement activation. ${ }^{17}$ This further indicates that PEGylated NPs may not necessarily behave as stealth entities depending on microenvironmental conditions.

In line with the above-mentioned issues, alternative strategies are being considered for design and engineering of long-circulating and macrophage-evading NPs. ${ }^{18}$ Among many approaches in NP surface engineering is surface functionalization with polyoxazoline polymers and their derivatives, which has generated promising outcomes. ${ }^{19-27}$ For instance, polyoxazoline-coated NPs show considerable resistance to protein binding and are more amenable to further chemical modifications compared with PEGylated NPs. ${ }^{28-30}$ Furthermore, polyoxazoline-coated NPs exhibit prolonged circulation profiles on intravenous injection in the murine model with comparable pharmacokinetic profiles to PEGylated NPs. ${ }^{27,31,32}$ Murine models and murine- and bovine-derived materials are widely used in nanomedicine evaluations. However, there are considerable species differences (e.g., mouse versus human) in innate immune responses to particulate invaders, including complement activation, C3 opsonization processes, and phagocytic clearance. For instance, although the uptake of superparamagnetic iron oxide nanoworms by both murine and human leukocytes is C3-dependent, there are major differences in pathways of complement activation and the extent of $\mathrm{C} 3$ fixation between these species. ${ }^{33}$ Accordingly, species differences in innate immune system function and performance can modulate NP pharmacokinetics and responses differently. Therefore, prior to translational and clinical studies, it is necessary to confirm stealth characteristics of engineered nanopharmaceuticals, at least with respect to the human complement system, blood leukocytes, and macrophage responses. Here, we have tested stealth characteristics of poly(2-methyl-2-oxazoline)-coated vinyltriethoxysilane-derived organically modified silica NPs (PMOXA-coated NPs) in human sera from different individuals against complement activation, complement opsonization, and dysopsonization processes and capturing efficacy by human blood leukocytes and monocyte-derived macrophages. Our approach has considered interindividual responses and highlights important insights into the mechanisms of compatibility of 
nanomaterials with elements of the human innate immunity and disparity with the murine system.

\section{RESULTS AND DISCUSSION}

\section{Synthesis and Physicochemical Properties of NPs.}

Polymeric NPs were prepared by ammonia-catalyzed microemulsion polymerization of vinyltrietoxysilane (VTES) (Figure 1A and Figures S1-S3). ${ }^{34}$ Fluorescent labeling and surface functionalization with PEG $\left(M_{\mathrm{W}}=2000 \mathrm{Da}\right.$, degree of polymerization $\left.=44\right)$ and PMOXA $\left(M_{\mathrm{W}}=4000 \mathrm{Da}\right.$, degree of polymerization $\left.=40\right)$ were achieved by copolymerizing VTES with Rhodamine B triethoxysilane and, when needed, with the trimethoxysilane derivatives of the polymers. ${ }^{1} \mathrm{H}$ NMR confirmed reaction completion and the absence of byproducts. Broadening of the ${ }^{1} \mathrm{H}$ NMR polymer signals (with respect to their corresponding linewidth in solution), as well as diffusion filter experiments, confirmed NP grafting with designated polymers (Figure S4). All NP types exhibited spheroidal morphology (determined by transmission electron microscopy, Figure S4) with calculated diameter (mean $\pm \mathrm{SD}$ ) of $115 \pm 23,90 \pm 10$, and $70 \pm 6(n=400)$ for uncoated, PEGylated, and PMOXA-coated species, respectively. NP hydrodynamic size distribution and concentration were also measured by nanoparticle tracking analysis (NTA). This modality overcomes intrinsic problems observed when DLS is applied to heterogeneous samples because it is based on video tracking of the Brownian motion of single NPs. ${ }^{35}$ The NTA results revealed mean hydrodynamic diameters (mean $\pm \mathrm{SD}$ ) of $144 \pm 5$ (mode $124 \pm 8$ ), 117 \pm 4 (mode $103 \pm 2$ ), and $86 \pm 4$ (mode $83 \pm 2$ ) for uncoated, PEGylated, and PMOXAcoated species ( $n=3$ measurements in all cases), respectively. Size distributions were almost symmetrical, with a $\pm \mathrm{D} 50 \%$ of $20-25 \mathrm{~nm}$ for all NPs. Dynamic laser light scattering yielded results comparable to those with NTA for all NP preparations with polydispersity indices $<0.04$, thus confirming near monodisperse NP suspensions. The small differences found in nanoparticle sizes are likely the result of the different additives (i.e., the alkoxysilane derivatives of the coating polymers) present in the reaction mixtures. Thermogravimetric analysis indicated approximately 13000 PEG molecules and 16000 PMOXA molecules per designated NP. These values correspond to surface footprints of 2.8 and $2.2 \mathrm{~nm}^{2}$ for PEG and PMOXA, respectively, and to a distance between grafting points of 1.9 and $1.7 \mathrm{~nm}$, respectively, which indicate that both the NP types feature a dense brush shell and that differences in their interfacial properties are solely due to their diverse shell composition (Table S4). Calculated $\zeta$-potential values of all engineered polymer-coated NPs $(-4 \mathrm{mV})$ were comparable with those of uncoated NPs $(-6 \mathrm{mV})$. All NP types exhibited comparable UV-visible spectra (Figure S4), and Rhodamine B loadings were in the $0.1-0.3 \%$ w/w range.

\section{Complement Activation Studies.}

NP-mediated complement activation in human serum (HS) was followed through measurement of a number of established complement activation products bound to NP surfaces as well as in the aqueous phase (see scheme in Figure 1B). Based on Western blot analysis, PMOXA-coated NPs were more effective in liberating C3a (the anaphylatoxin released on C3 cleavage) than both PEGylated and uncoated NPs (Figure 1C). The potency 
of PMOXA-coated NPs in activating the human complement system was further confirmed by showing the abundant presence of $\mathrm{C} 3 \mathrm{c} a^{\prime}$ chain fragment 2, which is generated after conversion of $\mathrm{C} 3 \mathrm{~b}$ into the inactive $\mathrm{C} 3 \mathrm{~b}$ (iC $3 \mathrm{~b}$ ), confirming $\mathrm{C} 3$ convertase activity as well as $\mathrm{Bb}$ generation (confirming the involvement of the alternative pathway of the complement system) compared with other NP species (Figure 1C). In addition to these, ELISA studies showed that PMOXA-coated NPs are far more efficient in liberating two markers of the terminal pathway of the human complement system (the anaphylatoxin C5a and sC5b-9, which is the soluble form of the membrane attack complex) than PEGylated and uncoated NPs on the basis of equivalent surface area (Figure 1D).

\section{Complement Activation Pathways Triggered by PMOXA-Coated NPs.}

PMOXA-coated NP-mediated Bb liberation confirms a role for the alternative pathway; however, it is not clear whether complement activation is solely arising from this pathway or if there is a role for both classical and lectin pathways and/or the amplification loop of the alternative pathway. It is well-known that the activation of the classical and lectin pathways of the complement system is $\mathrm{Ca}^{2+}$-dependent, whereas $\mathrm{Mg}^{2+}$ is essential for the operation of the alternative pathway. ${ }^{36,37}$ We found that selective chelation of serum $\mathrm{Ca}^{2+}$ (ethylene glycol-bis( $\beta$-aminoethyl ether)- $N, N, N^{\prime}, N^{\prime}$-tetraacetic acid (EGTA)/ $\mathrm{Mg}^{2+}$ treatment) strongly reduces PMOXA-coated NP-mediated $\mathrm{C} 3$ a release, whereas chelation of both $\mathrm{Ca}^{2+}$ and $\mathrm{Mg}^{2+}$ (ethylenediaminetetraacetic acid (EDTA) treatment) abolishes anaphylatoxin release (Figure 2A). Consistent with these observations, PMOXA-coated NP-induced generation of both $\mathrm{C} 5 \mathrm{a}$ and $\mathrm{sC} 5 \mathrm{~b}-9$ is dramatically reduced on $\mathrm{Ca}^{2+}$ chelation. On the other hand, prevention of the alternative pathway convertase stabilization by a neutralizing antiproperdin antibody abolished $\mathrm{Bb}$ generation and dramatically reduced $\mathrm{C5a}$ release and sC5b-9 formation on PMOXA-coated NP treatment. Furthermore, dot immunoblot studies (Figure 2B) showed that the binding of both $\mathrm{C} 3$ and properdin to PMOXA-coated NPs is affected by EGTA/ $\mathrm{Mg}^{2+}$ and essentially eliminated by EDTA. Collectively, these observations indicate that complement activation by PMOXA-coated NPs is predominantly initiated through $\mathrm{Ca}^{2+}$-sensitive pathways. Subsequently, this increases the turnover of the amplification loop of the alternative pathway to maximize $\mathrm{C} 3$ opsonization through assembly of the alternative pathway C3 convertase. In contrast to PMOXA-coated NPs, complement activation by uncoated and PEGylated NPs is marginal.

\section{Proteomic Analysis of Complement Protein Deposition on NPs.}

Next, we performed shot-gun proteomics after treatment of NPs with normal and chelated HS to gain more insights into complement activation processes (Figure 3A, Figures S5 and S6, and SI files 1-3). Among many deposited species, we detected several effector and regulatory components of the complement system (predominantly C1q, C1r, C1s, C3, C4, C5, C6, C7, C8, C9, B, P, C4Bp, CFAH, and related isoforms) on PMOXA-coated NPs. The surface presence of complement proteins was more prominent on PMOXA-coated NPs than PEGylated and uncoated NPs and in line with functional complement activation studies (Figure S6). However, there was a discrepancy between shot-gun and functional studies. Whereas functional studies confirmed a role for calcium-sensitive pathways, the second complement protein (C2) was not detectable by shot-gun profiling. Nevertheless, the general trend of shot-gun proteomics is in agreement with functional studies involving chelators as 
binding of the majority of complement proteins is dramatically reduced (>90\%) on calcium chelation and further inhibited on EDTA treatment of serum (Figure 3A and Figures S5 and S6). In contrast to complement proteins, other predominantly deposited species such as clusterin, lipoproteins (LPs), serum albumin, and immunoglobulins (Igs), are marginally affected on divalent cation chelation, regardless of NP type (Figure 3A and Figures S5 and S6).

MS spectrometry analysis, after in-gel digestions of major electrophoretic bands obtained by separation of the NP-bound HS polypeptides by SDS-PAGE, further agreed with shot-gun analysis (Figure 3B, Figure S7, and SI files 4-7). Notably, the bands corresponding to C3 $\beta$ chain $\left(M_{\mathrm{w}} \sim 65 \mathrm{kDa}\right)$ and $\mathrm{C} 3 \mathrm{c} a^{\prime}$ chain fragment $2\left(M_{\mathrm{w}} \sim 39 \mathrm{kDa}\right)$ were only detected under reducing conditions, which confirms $\mathrm{C} 3$ cleavage and covalent association of $\mathrm{C} 3 \mathrm{~b}$ with NP surfaces. Densitometry analysis of samples incubated in the presence of chelating agents, once again, showed that only the binding of complement proteins to PMOXA-coated NPs is strongly reduced on $\mathrm{Ca}^{2+}$ chelation and further inhibited on EDTA treatment (Figure 3B).

\section{Role of Human Serum and Complement Fixation on PMOXA-Coated NP Uptake by Human Phagocytes.}

Circulating blood phagocytes (monocytes and PMNGs (polymorphonuclear granulocytes)) and human macrophages showed preferential tendency to capture PMOXA-coated NPs and PEGylated NPs, compared with uncoated NPs, pretreated with HS (75\% v/v) for $15 \mathrm{~min}$ at $37^{\circ} \mathrm{C}$ in the absence of cells and then incubated with cells after a 10 -fold dilution in proteinfree culture medium (Figure 4A,B). Confocal fluorescent microscopy confirmed internalization of all preopsonized NPs and their localization to the acidic endosomallysosomal compartments (Figure 4C). Cell viability was further confirmed on NP uptake studies (Figure S8). Preopsonized NP uptake by both blood phagocytes and human macrophages, however, was dramatically reduced with $\mathrm{Ca}^{2+}$ chelation of serum (Figure 4B). This observation may suggest a likely role for complement activation and surface $\mathrm{C} 3$ fixation in NP recognition by human phagocytic cells. In contrast to human phagocytes, PMOXA-coated NPs were not only poor activators of the mouse complement system but also poorly recognized by mouse monocyte-derived macrophages compared with uncoated NPs (Figure 4D).

Next, we investigated whether complement activation and surface $\mathrm{C} 3$ fixation play a critical role in NP recognition by human phagocytes. Proteomic studies did not show significant surface association of collectins and associated proteases (e.g., mannose binding lectin (MBL), ficolins, collectin 11, and MBL-associated serine proteases, MASPs) ${ }^{38,39}$ with NPs. First, this observation excludes the potential involvement of these molecules and hence the lectin pathway in complement activation and $\mathrm{C} 3$ fixation. However, on the basis of the observed $\mathrm{C} 2$ discrepancy between shot-gun proteomics and functional complement activation studies, we sought to further investigate whether the lectin pathway of the complement plays a role in NP recognition by macrophages. There was no effect of mannose and $\mathrm{N}$-acetyl glucosamine (which compete with the binding of MBL and ficolins to their substrates) $)^{8,39}$ on NP uptake (Figure S9). Furthermore, aprotinin (a MASP inhibitor) ${ }^{40}$ did not affect the capture of PMOXA-coated NPs by macrophages (Figure S10). Following 
these studies, we measured macrophage uptake of NPs after incubation with HS depleted of various complement proteins (Figure 5). The results showed that the recognition of polymercoated NPs by macrophages is blocked by $>95 \%$ on $\mathrm{C} 3$ depletion, thereby suggesting a role for $\mathrm{C} 3 \mathrm{~b} / \mathrm{iC} 3 \mathrm{~b}$ as the major opsonic molecule and of cellular complement receptors 3 and 4 (Figure 5A). In addition, depletion from $\mathrm{HS}$ of either $\mathrm{C} 1 \mathrm{q}$ or $\mathrm{C} 4$ (which are required for assembly of the classical pathway $\mathrm{C} 3$ convertase) or factor B (which is required for increasing the turnover of the alternative pathway, and the amplification loop) strongly inhibited (77-86\%) capture of PMOXA-coated NPs by macrophages (Figure 5A). Addition of depleted factors to respective sera restored macrophage capabilities in capturing polymercoated NPs and comparable to levels seen in intact serum (Figure 5A). These observations confirm the role of complement activation and $\mathrm{C} 3$ surface fixation in NP capture by macrophages. Indeed, the results in Figure 5B confirm the notion that restoration of C1q in C1q-depleted serum triggers complement activation through the classical pathway and subsequent $\mathrm{C} 3$ cleavage.

Antibodies of both IgG and IgM classes are known to trigger activation of the classical pathway by facilitating C1q docking. Accordingly, complement activation by PMOXAcoated NPs may have been initiated through binding of either nonspecific or putative "PMOXA-specific" antibodies in human serum. Selective depletion of either IgM or IgG from HS did not significantly affect macrophage capture of PMOXA-coated NPs (Figures 5C and S11). Therefore, C1q-mediated complement activation by PMOXA-coated NPs is apparently antibody-independent. Subsequently, we showed that purified human C1q binds directly to PMOXA-coated NPs but not to uncoated NPs (Figure S12) with nanomolar affinity $\left(K_{\mathrm{d}}=11 \pm 1 \mathrm{nM}\right.$; maximal binding $=12 \pm 1 \mathrm{C} 1 \mathrm{q}$ molecules/NP). This is rather comparable with the affinity of C1q for some of its natural ligands such as DNA ( $K_{\mathrm{d}}=22$ $\mathrm{nM})$, histones, annexins, and $\operatorname{IgG}\left(K_{\mathrm{d}} \text { range }=1-2 \mathrm{nM}\right)^{41}$ and phosphatidylserine $\left(K_{\mathrm{d}}=37-\right.$ $70 \mathrm{nM}) .{ }^{42}$ For a comparative purpose, we also showed low affinity of pooled human $\mathrm{IgG}$ and lipoproteins (e.g., HDL) for PMOXA-coated NPs (Table 1 and Figure S13).

The globular head of $\mathrm{C} 1 \mathrm{q}$ is predominantly basic, which makes $\mathrm{C} 1 \mathrm{q}$ function as a charge pattern recognition molecule. ${ }^{43}$ Indeed, direct binding of the highly cationic C1qA chain to anionic liposomes (e.g., cardiolipin-containing vesicles) was demonstrated previously, which led to complement activation. ${ }^{44}$ In addition to this, C1q was also suggested to bind cardiolipin-containing liposomes and PEGylated vesicles through hydrophobic interactions and hydrogen bonding. ${ }^{44}$ Given the fact that the $\zeta$-potential of PMOXA-coated NPs is close to neutrality, it is most likely that direct $\mathrm{C} 1 \mathrm{q}$ association with these NPs could arise from hydrophobic interactions and/or hydrogen bonding by considering that in each PMOXA molecule there are about $40 \mathrm{C}=\mathrm{O}$ and $2 \mathrm{~S}=\mathrm{O}$ functionalities, and that $\mathrm{S}=\mathrm{O}$ groups are buried close to NP surfaces, whereas $\mathrm{C}=\mathrm{O}$ groups are distributed along the chains. It is also plausible that in serum/plasma, C1q may also function as a charge pattern recognition molecule by binding to exposed anionic domains of protein corona on PMOXA-coated NPs. 


\section{Effect of Sera Variability on Complement Activation, Protein Corona, and NP Uptake by Macrophages.}

Next, we compared the effect of sera from 8 individual donors on NP uptake by human phagocytes to account for interindividual variations in complement opsonic activities. The results in Figure 6A show that all 8 sera promoted efficient uptake of PMOXA-coated NPs by macrophages compared with uncoated NPs. In the case of PEGylated NPs, macrophage uptake was more variable and translated either to smaller, equal, or higher values than that of uncoated NPs, depending on serum donor. C3 $\beta$ chain densitometry analysis of NPs incubated with different sera (Figure 3B and Figures S7 and S14) also mirrored macrophage captures efficacies (Figure 6B). Comparative shot-gun proteomics further confirmed the above-mentioned observations, which correlated with C3 and properdin deposition on NPs, when tested in three representative sera displaying different macrophage capturing efficiency [(i) a serum that showed low macrophage capture of PEGylated NPs but high levels of PMOXA-coated NPs (donor A; PEG $^{\text {low }} / \mathrm{PMOXA}^{\text {high}}$ ), (ii) a serum promoting moderate/ intermediate capture of PEGylated NPs, yet high levels of PMOXA-coated NPs (donor D; $\mathrm{PEG}^{\text {intermediate/PMOXA }}{ }^{\text {high}}$ ), and (iii) a serum promoting high capture of both coated NP types by macrophages (donor F; PEG ${ }^{\text {high} / P M O X A ~}{ }^{\text {high}}$ )] (Figure 6C).

Furthermore, based on the label-free quantification parameter iBAQ, we observed no major quantitative differences in the protein corona for all NP types in the three sera (Figure S15, SI files 1-3 and 8-12). Subsequently, we compared the polypeptide composition of the corona (Figure S16, SI files 1-3 and 8-12). Clusterin and lipoproteins constituted major corona proteins from all sera. Although clusterin showed no clear preference for any specific NP type, Apo-AIV and Apo-E were consistently enriched on PEGylated NPs, whereas ApoCI, CII, CIII, and Apo-AII were preferentially associated with PMOXA-coated NPs. Uncoated NPs effectively bound all indicated apolipoproteins but with no clear selectivity. Finally, we statistically correlated the macrophage capture efficacy of polymer-coated NPs and the amount of those major protein classes consistently found in their corona through normalization (Figure 6D). As expected, the analysis showed a significant positive correlation between macrophage capture efficacy and the quantity of deposited $\mathrm{C} 3$ (Pearson's $R=0.9, p<0.05$ ) and properdin (Pearson's $R=0.93, p<0.01$ ). On the contrary, macrophage capturing efficacies of polymer-coated NPs did not significantly correlate with surface IgG (Pearson's $R=-0.17, p=0.75$ ) and IgM binding (Pearson's $R=0.57, p=0.24$ ). These observations corroborate with immunoglobulin depletion studies of HS and complement activation profiling. We also found no significant correlation between NP surface enrichment of clusterin, a protein reported to exhibit dysopsonic activity, ${ }^{45}$ and NP recognition by macrophages (Pearson's $R=-0.62, p=0.18$ ). Clusterin is a regulator of complement activity and is incorporated stoichiometrically into terminal complement complex, ${ }^{46-48}$ thereby inhibiting its lytic activity and proinflammatory effects. ${ }^{49}$ In accordance with complement activation properties of the tested NPs, and clusterin-mediated regulation of the complement by accelerating sC5b-9 formation, clusterin deposition on NP surfaces seems physiologically relevant. It is therefore possible that a fraction of surfacebound clusterin is in complex form with terminal complement $\mathrm{C} 7, \mathrm{C} 8 \mathrm{a}$, and $\mathrm{C} 9 \mathrm{~b}$ proteins. ${ }^{49}$ Furthermore, it is also known that clusterin circulates in plasma as a HDL complex with ApoA-I. ${ }^{50}$ Because clusterin deposition on NPs still occurs when the complement is 
inhibited (Figure 3 and Figures S5-S7), this may indirectly support the notion of direct HDL binding to NPs and/or clusterin-ApoA-I transfer from HDL to NP surfaces. Nevertheless, our data show that human macrophages can efficiently capture NPs on efficient C3 opsonization, despite NP surface enrichment with clusterin.

\section{CONCLUSIONS}

We demonstrated that NP coating with PMOXA, which confers "stealthing" properties in the murine environment, effectively activates the human complement system through $\mathrm{C} 1 \mathrm{q}$ binding independent of initial antibody deposition. C1q-mediated complement activation, in turn, enhanced $\mathrm{C} 3$ opsonization through the amplification loop of the alternative pathway. The extent of both C3 and properdin deposition on PMOXA-coated NPs correlated with human macrophage capture efficacy. We further showed that efficient $\mathrm{C} 3$ opsonization supersedes the proposed dysopsonic effect of clusterin and other corona proteins on NP surfaces. At large, our data show good correlation between proteomics and functional immune studies (with the exception of $\mathrm{C} 2$ protein) and further draw attention to the importance of testing nanomaterial immune compatibility with human materials, rather than relying on non-human sources (animal sera, cells, and in vivo studies in the murine model). Such disparities in immune handling of nanomaterials have also been observed among rodents. For example, in mice, intravenously injected ganglioside GM1-incorporated liposomes avoid rapid interception by macrophages of the RES, ${ }^{51}$ whereas in rats, such vesicles are not long-circulating. ${ }^{52}$ Rats, but not mice, produce natural anti-GM1 antibodies which, by triggering the classical complement pathway, likely mediate the clearance of GM1-containing liposomes by liver macrophages. Another example is the porcine model, which has been suggested for evaluating the safety (infusion reactions) of nanopharmaceuticals under development. ${ }^{16}$ However, a large body of evidence suggests that the porcine reactions are related to robust NP clearance by pulmonary intravascular macrophages (PIMs) and rapid release of arachidonate metabolites from these cells. ${ }^{17,53}$ Normal human lungs, however, do not have PIMs. Accordingly, testing of nanomedicine safety in porcine (and other animals with resident PIMs) will most likely induce cardiopulmonary distress, and therefore, global nanomedicine safety assessment in such species is perhaps inappropriate.

Finally, given the versatility of oxazoline-based polymers to further chemical modifications, future attempts may be directed to synthesize derivatives with no affinity for C1q binding and push the path toward engineering of oxazoline-coated NPs that evade recognition by elements of the human innate immune system.

\section{METHODS}

\section{Nanoparticle Preparation and Characterization.}

Details of all NP preparation and characterizations steps are provided in the supplementary files (S1-S4). For NTA, NPs were diluted in purified water $(182 \mathrm{M} \Omega \cdot \mathrm{cm})$ and tracks analyzed with Nanosight 2.3 software after acquisition with a LM20 NanoSight mounted with a blue (405 $\mathrm{nm}$ ) laser (Malvern Instruments, UK). A minimum of five different videos 
of individual NPs were pooled to define size distribution in three independent experiments per NP type.

\section{Cells.}

Blood was drawn from healthy volunteers and provided by the Blood Transfusion Centre of the Padova Hospital (Padova, Italy) complying with local regulations. Blood leukocytes were purified from buffy coats. Buffy coats were centrifuged $(800 \mathrm{~g}, 10 \mathrm{~min}, \mathrm{RT})$ and then treated twice with $155 \mathrm{mM} \mathrm{NH}_{4} \mathrm{Cl}, 10 \mathrm{mM} \mathrm{KHCO}_{3}$, and $100 \mathrm{mM} \mathrm{Na}_{2}$ EDTA at pH 7.4 for 5 $\mathrm{min}$ at room temperature to lyse erythrocytes. Leukocytes were then washed twice with PBS and used immediately. Forward versus side scatter gating in FACS allowed separation and analysis of the three different cell populations (lymphocytes, monocytes, and PMNGs). Human macrophages were derived from blood monocytes incubated for 7 days with 100 $\mathrm{ng} / \mathrm{mL}$ of macrophage colony-stimulating factor (M-CSF, Peprotech, UK) in RPMI 1640 (Invitrogen, CA, USA) supplemented with $20 \%$ (v/v) fetal calf serum (Euroclone, Italy, endotoxin $<0.3 \mathrm{EU} / \mathrm{mL}$ ), $100 \mathrm{U} / \mathrm{mL}$ penicillin, and $100 \mu \mathrm{g} / \mathrm{mL}$ streptomycin). ${ }^{54}$ Human PMNGs were purified from healthy donors as previously described using dextran sedimentation, centrifugation through Ficoll-Paque, followed by hypotonic lysis of contaminating erythrocytes and washing with PBS. ${ }^{55}$ To obtain mouse bone marrow macrophages, femurs and tibiae of Balb/c animals, previously subjected to cervical dislocation, were flushed with Iscove's modified Dulbecco's medium (IMDM, Thermo Fisher Scientific, MA, USA). After lysis of red blood cells with ammonium-chloridepotassium lysis buffer ( $5 \mathrm{~min}$ at room temperature), leukocytes were recovered from the obtained cell suspension, and mononuclear phagocytic precursor cells were propagated in suspension in IMDM containing 10\% v/v FBS (Thermo Fisher Scientific), $100 \mathrm{U} / \mathrm{mL}$ penicillin, $100 \mu \mathrm{g} / \mathrm{mL}$ streptomycin (Thermo Fisher Scientific), and $10 \mathrm{ng} / \mathrm{mL}$ M-CSF (Miltenyi, Germany). ${ }^{56}$ After being cultured at $37{ }^{\circ} \mathrm{C}$ in a humidified incubator with $5 \%$ $\mathrm{CO}_{2}$ for 3 days, one-half of the medium was replaced with a fresh one, and cells were further incubated for 4 days to obtain their differentiation into macrophages.

\section{Human and Mouse Sera.}

Venous blood from healthy human donors was collected into BD Vacutainer clot activator tube (Becton Dickinson, NJ, USA). Experiments with human sera were performed under local guidelines. After clotting at room temperature, blood samples were centrifuged at $1250 \mathrm{~g}$ for $5 \mathrm{~min}$ to obtain sera. Collected sera were aliquoted and stored at $-80^{\circ} \mathrm{C}$. Before use, serum was thawed at $37{ }^{\circ} \mathrm{C} .{ }^{57}$ Independent commercially pooled HS preparations from at least six donors were provided by CompTech (TX, USA) and used when indicated. C1q-, C3-, C4-, and factor-B-depleted sera and purified C1q, C3, C4, and factor B were purchased from CompTech. For IgM depletion, HS was incubated with anti-human IgM agarose beads (Sigma, MO, USA) ${ }^{58}$ Prechilled agarose beads $(0.2 \mathrm{~mL}$ packed) equilibrated in cold PBS were mixed with $0.2 \mathrm{~mL}$ of $\mathrm{HS}$ and $0.5 \mathrm{mM}$ EDTA, and the suspension was mixed at $4{ }^{\circ} \mathrm{C}$ for $60 \mathrm{~min}$. Agarose beads were pelleted by centrifugation, and the incubation step was repeated with fresh resin. IgM-depleted serum was then recovered and immediately frozen in liquid nitrogen. On the day of the experiment with macrophages, physiological $\mathrm{Ca}^{2+}$ and $\mathrm{Mg}^{2+}$ levels were restored during incubation with cells. To recover bound IgM, beads were treated with $500 \mu \mathrm{L}$ of $100 \mathrm{mM}$ glycine, $\mathrm{pH} 2.8$ (Sigma), for 5 min and centrifuged. To the 
recovered supernatant was added $50 \mu \mathrm{L}$ of $1 \mathrm{M}$ Tris- $\mathrm{HCl}$ (Sigma) to restore physiological $\mathrm{pH}$; this procedure was repeated three times and then dialyzed overnight at $4{ }^{\circ} \mathrm{C}$ against PBS. Finally, IgM was concentrated in Microcon tubes (Millipore, MA, USA), and protein concentration was measured by Bradford assay (Biorad, CA, USA). For the depletion of IgG antibodies, HS was incubated with protein A sepharose (Amersham, UK). To $200 \mu \mathrm{L}$ of HS (supplemented with $0.5 \mathrm{mM}$ EDTA) was added and mixed $200 \mu \mathrm{L}$ of packed protein A beads at $4{ }^{\circ} \mathrm{C}$ for $60 \mathrm{~min}$. Sepharose beads were removed by centrifugation, and the follow-up treatments and $\mathrm{IgG}$ recovery procedures were the same as those for $\operatorname{IgM}$. Depletion of IgM and $\mathrm{IgG}$ from sera was confirmed by immunoblotting. Here, $0.5 \mu \mathrm{L}$ of designated serum was mixed with $50 \mu \mathrm{L}$ of PBS, and then $12 \mu \mathrm{L}$ of sample containing loading buffer was loaded onto a 6 or $8 \%$ gel. Following SDS-PAGE, proteins were blotted onto nitrocellulose paper (Biorad) for $1 \mathrm{~h}$. The membrane was blocked with TBS-T (50 mM Tris-HCl, $\mathrm{pH} 7.5,100$ $\mathrm{mM} \mathrm{NaCl}, 0.1 \% \mathrm{w} / \mathrm{v}$ Tween 20 ) containing $3 \% \mathrm{w} / \mathrm{v}$ nonfat milk overnight at $4{ }^{\circ} \mathrm{C}$. Finally, the membrane was incubated with anti-IgM-HRP antibodies (Sigma) or anti-IgG-HRP antibodies (Merck, Germany) for $1 \mathrm{~h}$ at room temperature, and proteins were detected by a Huvitec (Eppendorf, Germany) image analyzer. Pooled mouse serum was prepared from the blood of 12 adult healthy male and female BALB/c mice. Blood clotting and retraction was allowed to take place spontaneously at room temperature following procedures outlined by Lachmann. ${ }^{59}$ The initial centrifugation was carried out at $3000 \mathrm{~g}$ for $5 \mathrm{~min}$ at room temperature to obtain serum. A second high-speed centrifugation was performed to remove contaminated blood cells at $20000 \mathrm{~g}$ for $2 \mathrm{~min}$. Fresh serum from the second centrifugation was not frozen but was used immediately for biological experiments.

\section{NP Binding to Cells.}

Intracellular distribution of fluorescent NPs was assessed by confocal microscopy. Macrophages $\left(2 \times 10^{6}\right)$ seeded on glass slides were washed with PBS (Invitrogen) and incubated for $3 \mathrm{~h}$ at $37{ }^{\circ} \mathrm{C}$ with NPs, preincubated with $75 \%$ (v/v) HS for $15 \mathrm{~min}$ at $37^{\circ} \mathrm{C}$, and then diluted in RPMI. Following incubation, the medium was removed, and cells were washed with PBS and incubated for 30 min with $75 \mathrm{nM}$ LysoTracker Green DND-26 (Invitrogen) for endolysosomal staining and then directly analyzed by confocal microscopy (Leica SP2, Germany). Images were processed using ImageJ software. For FACS analysis, NPs $(200-800 \mu \mathrm{g} / \mathrm{mL})$ were preincubated with $75 \% \mathrm{v} / \mathrm{v}$ for $20 \mathrm{~min}$ at $37^{\circ} \mathrm{C}$. For control experiments, NPs were incubated in PBS. NPs were then diluted with RPMI medium and incubated with cells $\left(10^{6}\right.$ cells/well for leukocytes and macrophages) for $3 \mathrm{~h}$ at $37^{\circ} \mathrm{C}$. Cells were than washed with PBS, resuspended in FACS buffer (1\% FBS in PBS), and analyzed by cytofluorimetry (FACSCantoII, Becton Dickinson). Data were analyzed by FACSDiva software (BD) and expressed as MFI (mean fluorescence intensity) values, normalized based on intrinsic quantum yield of different NPs types and batches. In some experiments, the incubation of NPs with HS was performed in the presence of $10 \mathrm{mM} \mathrm{EGTA/2} \mathrm{mM} \mathrm{MgCl} 2$ or $10 \mathrm{mM}$ EDTA to chelate $\mathrm{Ca}^{2+}$ or both $\mathrm{Ca}^{2+}$ and $\mathrm{Mg}^{2+}$, respectively, before dilution as above in culture medium for cell uptake measurements. In some experiments, samples were incubated in the presence of $25 \mathrm{mM}$ D-mannose, $N$-acetylglucosamine (inhibitors of lectin complement pathway) or D-galactose (as control), and $5 \mu \mathrm{M}$ aprotinin (Sigma) and further diluted in cell culture medium in the presence of the same inhibitors. 


\section{NP Protein Corona Determination by Shot-Gun Proteomics.}

Uncoated, PEGylated, or PMOXA-coated NPs $(800 \mu \mathrm{g} / \mathrm{mL})$ were incubated under stirring at $37{ }^{\circ} \mathrm{C}$ for 15 min in RPMI 1640 supplemented with $100 \mu \mathrm{L}$ of $75 \%$ (v/v) HS. NPs were washed three times with $1 \mathrm{~mL}$ of ice-cold PBS (pH 7.4) and then recovered by centrifugation (30 min, $21000 \mathrm{~g}$ at $4{ }^{\circ} \mathrm{C}$ ). NP-protein pellets were resuspended in $8 \mathrm{M}$ urea $/ 50 \mathrm{mM} \mathrm{NH} \mathrm{HCO}_{3}$ (Sigma). Disulfide bonds were reduced with $5 \mathrm{mM}$ TCEP (Sigma) for $30 \mathrm{~min}$ and alkylated with $40 \mathrm{mM}$ iodacetamide (Fluka, Mexico) at room temperature in the dark. The content of urea was brought to $6 \mathrm{M}$ with $50 \mathrm{mM} \mathrm{NH}_{4} \mathrm{HCO}_{3}$, and $1-100 \%$ (w/w) of LysC (Promega) was added to each sample for $6 \mathrm{~h}$ at $37^{\circ} \mathrm{C}$. Samples were diluted five times with $50 \mathrm{mM} \mathrm{NH}_{4} \mathrm{HCO}_{3}$ to obtain a urea concentration of $1.2 \mathrm{M}$ during trypsin digestion. A $1-50 \%(w / w)$ of sequencing-grade-modified trypsin (Promega) was added to the protein sample, and digestion was carried out at $37^{\circ} \mathrm{C}$ overnight. Samples were then centrifuged at $18000 \mathrm{~g}$ for $30 \mathrm{~min}$ at $4{ }^{\circ} \mathrm{C}$ to remove NPs and desalted using $\mathrm{C} 18$ cartridges (Sep Pak, Waters, France) according to manufacturer's instructions. All samples were treated simultaneously and exactly in the same way to allow a quantitative comparison of the MS data. Samples were then dried under vacuum and suspended in $24 \mu \mathrm{L}$ of $3 \%(\mathrm{v} / \mathrm{v})$ acetonitrile/0.1\% (v/v) formic acid. Next, $2 \mu \mathrm{L}$ of each sample was analyzed by LC-MS/MS on a LTQ-Orbitrap XL mass spectrometer (ThermoFisher Scientific) coupled online to a nano-HPLC Ultimate 3000 (Dionex-ThermoFisher Scientific) as described earlier. ${ }^{60}$ Peptides bound to pico-frit columns (New Objective, NJ, USA) packed with C18 material (Aeris Peptide $3.6 \mathrm{mmXBC18}$; Phenomenex, CA, USA, flow rate $=8 \mu \mathrm{L} / \mathrm{min}$ ) were separated with an acetonitrile/0.1\% (v/v) formic acid gradient (from 3 to $40 \%$ in $45 \mathrm{~min}$, flow rate $=250 \mathrm{~nL} / \mathrm{min}$ ). Ion source capillary temperature was $200{ }^{\circ} \mathrm{C}$, and spray voltage was set to $1.2-1.3 \mathrm{kV}$. The instrument operated in a data-dependent mode with a full scan at 60000 resolution on the Orbitrap followed by MS/MS fragmentation in the linear trap of the four most intense ions.

\section{Protein Identification.}

Raw data files were processed using the software Proteome Discoverer 1.4 (ThermoFisher Scientific) interfaced to a Mascot server (version 2.2.4; Matrix Science, MA, USA) and the software MaxQuant (version 1.5.1.2) ${ }^{61}$ integrated with the Andromeda search engine. ${ }^{62}$ Protein identification was performed against the human section of the Uniprot database (version 20150401; 9411 sequences). Enzyme specificity was set to trypsin with a maximum of two missed cleavages allowed. Precursor and fragment mass tolerances were set to 10 ppm and 0.6 Da, respectively. Carbamidomethylation of cysteine residues and methionine oxidation were set as a static and dynamic modification, respectively. For data obtained with Proteome Discoverer, the algorithm Percolator was used to assess peptide and protein identification confidence. ${ }^{63}$ Data were filtered to account only for proteins identified with at least two independent unique peptides with high confidence $(q \leq 0.01)$. Proteins were grouped into protein families according to the principle of maximum parsimony. Label-free quantification was obtained with the precursor ion area detector node, which extracts and integrated the area under the peak for each identified peptide and estimates the amount of protein by averaging the area under the peak of identified peptides for each protein (intensity). Therefore, quantitative intensity data are associated only with proteins identified with at least three independent peptides. For data obtained with the software MaxQuant, the 
intensity of each peptide and the intensity-based absolute protein quantification (iBAQ) parameter (described in ref 64) were automatically calculated by the software. Data were manually filtered to keep into account only proteins identified with at least four unique peptides per identified proteins.

\section{Estimation of Polypeptide Stoichiometry and Mass in NP Corona.}

The approximate polypeptide composition of the NP corona was calculated by taking into account the size and density of NPs (mean diameter of $100 \mathrm{~nm}$ and density around $1.5 \mathrm{~g} / \mathrm{mL}$, leading to a $M_{\mathrm{w}}$ of $\sim 5 \times 10^{8} \mathrm{Da}$ for all NPs) and then using proteomics label-free parameter iBAQ (4 peptide cutoff). Based on the above information, a ratio of 1 clusterin molecule (49 $000 \mathrm{Da}$ ) per NP would lead to a weight ratio of $0.01 \mu \mathrm{g}$ clusterin/100 $\mu \mathrm{g}$ of NPs. Hence, using values of the experimentally determined percent amount of total protein (associated with $100 \mu \mathrm{g}$ of NPs) (\% w protein), we used the following equation to obtain clusterin stoichiometry (number of polypeptide/NPs):

$$
\text { clusterin } / \mathrm{NP} \text { stoichiometry }=\left[\left(M_{\mathrm{w}} \text { clusterin } \times \mathrm{iBAQ} \text { clusterin } / \sum M_{\mathrm{w}, n} \mathrm{iBAQ}_{n}\right) \times \% \mathrm{w} \text { proteins }\right] \times 0.01^{-1}
$$

The stoichiometry of other polypeptides was derived by their respective iBAQ values, compared to that of clusterin ( polypeptide $_{n} / \mathrm{NP}=$ number of clusters $/ \mathrm{NPs} \times\left(\mathrm{iBAQ}_{n}\right)$ $\left.i B A Q_{\text {clusterin }}\right)$. The mass amount was determined based on the molecular weight of a given polypeptide and the Avogadro number using the equation

$$
\text { weight of one polypeptide }{ }_{n}=\left[M_{\mathrm{w}, n}(\mathrm{KDa}) / 6.022\right] \times 10^{-20} \mathrm{gr}
$$

\section{SDS-PAGE and Staining.}

Uncoated, PEGylated, and PMOXA-coated NPs $(800 \mu \mathrm{g} / \mathrm{mL})$ were incubated under stirring at $37{ }^{\circ} \mathrm{C}$ for $15 \mathrm{~min}$ in RPMI 1640 supplemented with $100 \mu \mathrm{L}$ of $75 \%$ (v/v) HS. NPs were washed three times with $1 \mathrm{~mL}$ of ice-cold PBS, $\mathrm{pH} 7.4$, and recovered by centrifugation (30 $\min , 21000 \mathrm{~g}$ at $4{ }^{\circ} \mathrm{C}$ ). The NP-protein pellet was dissolved in $25 \mu \mathrm{L}$ of loading sample buffer (62.5 mM Tris-HCl, pH 6.8, 2\% w/v SDS, $25 \%$ v/v glycerol, $0.01 \%$ w/v bromophenol blue, with or without $\beta$-mercaptoethanol). After being heated at $95^{\circ} \mathrm{C}$ for $5 \mathrm{~min}$, equal volumes $(12 \mu \mathrm{L})$ of samples were subjected to SDS-PAGE in 8 or $12 \%$ acrylamide gels. After being heated at $95{ }^{\circ} \mathrm{C}$ for $5 \mathrm{~min}$, equal volumes $(12 \mu \mathrm{L})$ of samples were subjected to SDS-PAGE ( 8 or $12 \%$ acrylamide). NP-independent protein recovery was assessed by running mock samples in protein media. Silver or Coomassie G-250 staining (for mass spectrometry) was used to reveal separated polypeptides. For silver staining, gels were fixed for $30 \mathrm{~min}$ in $50 \% \mathrm{v} / \mathrm{v}$ methanol $10 \% \mathrm{v} / \mathrm{v}$ acetic acid and then incubated for $15 \mathrm{~min}$ in 5\% $\mathrm{v} / \mathrm{v}$ methanol, $1 \% \mathrm{v} / \mathrm{v}$ acetic acid, washed three times with water, and exposed for $90 \mathrm{~s}$ to thiosulfate solution ( $200 \mu \mathrm{g} / \mathrm{mL} \mathrm{Na}_{2} \mathrm{~S}_{2} \mathrm{O}_{3}$ pentahydrate). After extensive washing with water, gels were incubated in the dark for 30 min with $0.2 \mathrm{~g} / \mathrm{L} \mathrm{AgNO}_{3}$, rinsed, and developed for 5-15 min with a solution containing $60 \mathrm{mg} / \mathrm{mL} \mathrm{Na}_{2} \mathrm{CO}_{3}, 4 \mu \mathrm{g} / \mathrm{mL} \mathrm{Na}_{2} \mathrm{~S}_{2} \mathrm{O}_{3}$ pentahydrate, and $0.01875 \% \mathrm{v} / \mathrm{v}$ formaldehyde. Reaction was stopped with $6 \% \mathrm{v} / \mathrm{v}$ acetic acid. For colloidal Coomassie G-250 staining, gels were fixed for $18 \mathrm{~h}$ in $50 \% \mathrm{v} / \mathrm{v}$ methanol and $2 \%$ 
$\mathrm{v} / \mathrm{v} \mathrm{H}_{3} \mathrm{PO}_{4}$, rinsed three times for $30 \mathrm{~min}$ with water, and incubated for $1 \mathrm{~h}$ in a solution containing $34 \% \mathrm{v} / \mathrm{v}$ methanol, $2 \% \mathrm{v} / \mathrm{v} \mathrm{H}_{3} \mathrm{PO}_{4}$, and $17 \% \mathrm{w} / \mathrm{v}\left(\mathrm{NH}_{4}\right)_{2} \mathrm{SO}_{4}$. Staining was performed for 3 days in 34\% v/v methanol, $2 \% \mathrm{v} / \mathrm{v} \mathrm{H}_{3} \mathrm{PO}_{4}, 17 \% \mathrm{w} / \mathrm{v}\left(\mathrm{NH}_{4}\right)_{2} \mathrm{SO}_{4}$, and $0.066 \%$ w/v Coomassie G-250, and it was followed by destaining in water for an additional 3 days. Band densitometry was performed using ImageJ software, after background subtraction. In separate experiments, the protein content after corona formation was determined by Bradford assay after washings. Bovine serum albumin (Sigma) was used as the reference protein.

\section{Protein Identification after In-Gel Digestion.}

Bands from SDS-PAGE were washed with 50\% v/v acetonitrile (ACN) in $0.1 \mathrm{M} \mathrm{NH}_{4} \mathrm{HCO}_{3}$, vacuum-dried, treated for $30 \mathrm{~min}$ at $56{ }^{\circ} \mathrm{C}$ with $10 \mathrm{mM} \mathrm{DTT}$ in $0.1 \mathrm{M} \mathrm{NH}_{4} \mathrm{HCO}_{3}$, cooled at $25{ }^{\circ} \mathrm{C}$, and further incubated in the dark for $20 \mathrm{~min}$ with $55 \mathrm{mM}$ iodacetamide in $0.1 \mathrm{M}$ $\mathrm{NH}_{4} \mathrm{HCO}_{3}$ to alkylate thiols. After being washed with $50 \% \mathrm{ACN}$ in $0.1 \mathrm{M} \mathrm{NH}_{4} \mathrm{HCO}_{3}$, the dried gel pieces were swollen and treated overnight at $37{ }^{\circ} \mathrm{C}$ with $15 \mu \mathrm{L}$ of digestion buffer ( $12.5 \mathrm{ng} / \mu \mathrm{L}$ trypsin, Promega, in $25 \mathrm{mM} \mathrm{NH}_{4} \mathrm{HCO}_{3}$ ). The obtained peptides, extracted as detailed by Kim et at. ${ }^{65}$ were analyzed by LC-MS/MS on a 6520 Q-TOF mass spectrometer (Agilent Technologies) coupled to a chip-based chromatographic interface. Large capacity chips $(\mathrm{C} 18,150 \mu \mathrm{m} \times 75 \mu \mathrm{m})$ and enrichment columns $(\mathrm{C} 18,9 \mathrm{~mm}, 160 \mathrm{~nL}$ volume, $0.3 \mu \mathrm{L} /$ min) were employed for peptide separation. Eluting solutions A (water/formic acid $0.1 \%$ $\mathrm{v} / \mathrm{v}$ ) and B (acetonitrile/formic acid $0.1 \% \mathrm{v} / \mathrm{v}$ ) were used. A gradient of solution B from 5 to $50 \%$ in 20 min allowed effective chromatographic resolution. Raw data, converted into mascot generic format with MassHunter qualitative analysis software version B.03.01 (Agilent Technologies), were analyzed with Mascot Search Engine version 2.2.4 (Matrix Science). MS/MS spectra were screened versus SwissProt database (June 2014 version, Taxonomy Mammalia, 66370 peptide entries). Enzyme specificity was set to trypsin/P with two missed cleavage (mass tolerance $20 \mathrm{ppm}$ for parent mass and 0.6 Da for fragment ions). Cysteine carbamidomethylation and methionine oxidation were set as fixed or variable modifications, respectively. Positivity cut off: more than 1 peptide per protein $(p<0.05)$.

\section{Western Blot, Dot Blot, and ELISA Assays of Complement Proteins and Fragments.}

Western Blot.-To control complement activity, $25 \mu \mathrm{L}$ of HS was treated with $6.25 \mu \mathrm{L}$ of Zymosan $(25 \mathrm{mg} / \mathrm{mL}$, Sigma, prepared as described by manufacturer's instructions) at $37^{\circ} \mathrm{C}$. The reaction was terminated after $30 \mathrm{~min}$ with $25 \mathrm{mM}$ EDTA. To assess complement activation induced by NPs, $25 \mu \mathrm{L}$ of HS was incubated with $800 \mu \mathrm{g} / \mathrm{mL}$ of different NP preparations for $30 \mathrm{~min}$ at $37^{\circ} \mathrm{C}$. Then $1.6 \mu \mathrm{L}$ of each sample was mixed with $38.4 \mu \mathrm{L}$ of water and $6.7 \mu \mathrm{L}$ of loading buffer without $\beta$-mercaptoethanol, and $15 \mu \mathrm{L}$ of sample was loaded onto an 8 or $12 \%$ gel. Polypeptides were then transferred to nitrocellulose membranes (Biorad) which, after saturation with TBS-T containing $1 \%$ nonfat milk at room temperature for $1 \mathrm{~h}$, were further treated in the same solution with antibodies against $\mathrm{C} 3 \mathrm{a}$ or B factor (Calbiochem, 1:2000) overnight at $4{ }^{\circ} \mathrm{C}$. Membranes were washed three times with TBS $/ 0.1 \%$ v/v Tween 20 and treated with secondary HRP-(Calbiochem) or FITC (Millipore)-conjugated Abs. Proteins were detected by Huvitec (Eppendorf) or Odissey CLx (Li-cor) imaging systems. 
Dot Blot.-For the binding assay of complement proteins, NPs were treated with $\mathrm{HS}$ at a $1: 3(\mathrm{v} / \mathrm{v})$ ratio (routinely mixing $10 \mu \mathrm{L}$ of NPs $3 \mathrm{mg} / \mathrm{mL}$ and $30 \mu \mathrm{L}$ of HS) with or without $10 \mathrm{mM}$ EDTA, $10 \mathrm{mM}$ EGTA/Mg${ }^{2+}$, or antiproperdin antibodies (10 folds diluted). NP concentrations were quantified with NanoSight (Malvern Instruments). After being washed three times by centrifugation in PBS plus $\mathrm{Ca}^{2+} / \mathrm{Mg}^{2+}$ at $4{ }^{\circ} \mathrm{C}$ (Beckman Optima TLX ultracentrifuge, $150000 \mathrm{~g}$ ), NP pellets were resuspended in $20 \mu \mathrm{L}$ of PBS, and bound proteins were detached by $2 \%$ SDS and quantified. Two microliter triplicate sample aliquots were blotted on a $0.2 \mu \mathrm{m}$ pore nitrocellulose membrane (Bio-Rad) which was then saturated with 5\% (w/w) nonfat dry milk in PBS-T (1X PBS with $0.1 \%$ Tween 20 ) for $1 \mathrm{~h}$ at room temperature. Membranes were incubated with anticomplement protein specific antibodies for $1 \mathrm{~h}$ at room temperature, washed three times with PBS-T, and eventually challenged for 1 $\mathrm{h}$ with IRDye 800CW-labeled secondary antibodies. Intensities of scanned bot images, obtained with an Odyssey infrared imager (Li-COR Biosciences, Lincoln, NE, US), were measured using ImageJ software.

ELISA.-Complement activation in HS was quantified by testing the NP-induced rise of complement activation products $\mathrm{C} 5 \mathrm{a}, \mathrm{Bb}$, and sC5b-9 with Quidel (Quidel, CA, USA) kits as detailed. ${ }^{17,66}$ NPs were added to $75 \%$ (v/v) HS in Eppendorf tubes (in triplicate) in a shaking water bath at $37^{\circ} \mathrm{C}$ for $30 \mathrm{~min}$. Reactions were terminated by addition of "sample diluent" provided with the assay kit or saline containing $25 \mathrm{mM}$ EDTA. NP-induced rises of serum complement activation products were then measured following reaction termination with "sample diluent" from kits or saline supplemented with $25 \mathrm{mM}$ EDTA and NP removal. Background complement activation was estimated by incubating HS with saline. In some cases, the assay was performed in the presence of $10 \mathrm{mM} \mathrm{EGTA} / 2.5 \mathrm{mM} \mathrm{MgCl}_{2}$ or antiproperdin antibodies or of Zymosan as a positive control.

\title{
Statistical Analysis.
}

Mean difference significances ( 0.05 level) were assessed by two samples or paired $t$ test, when appropriate, using the Microcal Origin 8 software, after checking the Gaussian distribution (Shapiro-Wilk test, 0.05 level). Pearson correlation coefficient, $R$, its significance ( $t$ test), and linear regression analysis parameters were calculated using the Excell2000 software statistics package. The number of independent experiments and mean values \pm SE are indicated where appropriate.

\section{Supplementary Material}

Refer to Web version on PubMed Central for supplementary material.

\section{ACKNOWLEDGMENTS}

\begin{abstract}
We thank the Centro Trasfusionale of the Hospital of Padua (ULSS 16) for providing human blood buffy coats, and Dr. Fabio Munari of the Venetian Institute for Molecular Medicine (VIMM) in Padova for helping in murine macrophage preparations. Part of the data presented was obtained by AG.-S. in partial fulfilment of the requirements for her Ph.D. degree in Biomedical Sciences at the University of Padova. This work was supported by the University of Padova (Ex 60\% and DOR, 2014-2015-2016-2017-2018), and Strategic Project NAMECA. S.M.M. acknowledges financial support by the International Science and Technology Cooperation of Guangdong Province (reference 2015A050502002) and Guangzhou City (reference 2016201604030050) with RiboBio Co,
\end{abstract}


Ltd., China. L.-P.W. acknowledges financial support from Drug Discovery Pipeline of Guangzhou Institutes of Biomedicine and Health.

\section{REFERENCES}

(1). Moghimi SM; Hunter AC; Andresen TL Factors Controlling Nanoparticle Pharmacokinetics: An Integrated Analysis and Perspective. Annu. Rev. Pharmacol. Toxicol 2012, 52, 481-503. [PubMed: 22035254]

(2). Moghimi SM; Parhamifar L; Ahmadvand D; Wibroe PP; Andresen TL; Farhangrazi ZS; Hunter AC Particulate Systems for Targeting of Macrophages: Basic and Therapeutic Concepts. J. Innate Immun 2012, 4, 509-528. [PubMed: 22722900]

(3). Salvati A; Pitek AS; Monopoli MP; Prapainop K; Bombelli FB; Hristov DR; Kelly PM; Aberg C; Mahon E; Dawson KA Transferrin-Functionalized Nanoparticles Lose Their Targeting Capabilities When a Biomolecule Corona Adsorbs on the Surface. Nat. Nanotechnol 2013, 8, 137-143.

(4). Maiolo D; Del Pino P; Metrangolo P; Parak WJ; Baldelli Bombelli F Nanomedicine Delivery: Does Protein Corona Route to the Target or off Road? Nanomedicine (London, U. K.) 2015, 10, 3231-3247. [PubMed: 26470748]

(5). Suk JS; Xu Q; Kim N; Hanes J; Ensign LM PEGylation as a Strategy for Improving NanoparticleBased Drug and Gene Delivery. Adv. Drug Delivery Rev 2016, 99, 28-51.

(6). Gabizon A; Shmeeda H; Barenholz Y Pharmacokinetics of Pegylated Liposomal Doxorubicin: Review of Animal and Human Studies. Clin. Pharmacokinet 2003, 42, 419-436. [PubMed: 12739982]

(7). Moghimi SM; Hunter AC; Dadswell CM; Savay S; Alving CR; Szebeni J Causative Factors behind Poloxamer 188 (Pluronic F68, Flocor)-Induced Complement Activation in Human Sera. A Protective Role against Poloxamer-Mediated Complement Activation by Elevated Serum Lipoprotein Levels. Biochim. Biophys. Acta, Mol. Basis Dis 2004, 1689, 103-113.

(8). Hamad I; Hunter AC; Szebeni J; Moghimi SM Poly(ethylene Glycol)s Generate Complement Activation Products in Human Serum through Increased Alternative Pathway Turnover and a MASP-2-Dependent Process. Mol. Immunol 2008, 46, 225-232. [PubMed: 18849076]

(9). Armstrong JK; Hempel G; Koling S; Chan LS; Fisher T; Meiselman HJ; Garratty G Antibody against Poly(ethylene Glycol) Adversely Affects PEG-Asparaginase Therapy in Acute Lymphoblastic Leukemia Patients. Cancer 2007, 110, 103-111. [PubMed: 17516438]

(10). Zhao Y; Wang L; Yan M; Ma Y; Zang G; She Z; Deng Y Repeated Injection of PEGylated Solid Lipid Nanoparticles Induces Accelerated Blood Clearance in Mice and Beagles. Int. J. Nanomed 2012, 7, 2891-2900.

(11). Suzuki T; Ichihara M; Hyodo K; Yamamoto E; Ishida T; Kiwada H; Ishihara H; Kikuchi H Accelerated Blood Clearance of PEGylated Liposomes Containing Doxorubicin upon Repeated Administration to Dogs. Int. J. Pharm 2012, 436, 636-643. [PubMed: 22850293]

(12). Ma Y; Yang Q; Wang L; Zhou X; Zhao Y; Deng Y Repeated Injections of PEGylated Liposomal Topotecan Induces Accelerated Blood Clearance Phenomenon in Rats. Eur. J. Pharm. Sci 2012, $45,539-545$.

(13). Le Y; Toyofuku WM; Scott MD Immunogenicity of Murine mPEG-Red Blood Cells and the Risk of Anti-PEG Antibodies in Human Blood Donors. Exp. Hematol 2017, 47, 36-47. [PubMed: 27864153]

(14). Arima Y; Toda M; Iwata H Complement Activation on Surfaces Modified with Ethylene Glycol Units. Biomaterials 2008, 29, 551-560. [PubMed: 17981322]

(15). Szebeni J; Muggia F; Gabizon A; Barenholz Y Activation of Complement by Therapeutic Liposomes and Other Lipid Excipient-Based Therapeutic Products: Prediction and Prevention. Adv. Drug Delivery Rev 2011, 63, 1020-1030.

(16). Dezsi L; Fulop T; Meszaros T; Szenasi G; Urbanics R; Vazsonyi C; Orfi E; Rosivall L; Nemes R; Kok RJ; Metselaar JM; Storm G; Szebeni J Features of Complement Activation-Related Pseudoallergy to Liposomes with Different Surface Charge and PEGylation: Comparison of the Porcine and Rat Responses. J. Controlled Release 2014, 195, 2-10. 
(17). Wibroe PP; Anselmo AC; Nilsson PH; Sarode A; Gupta V; Urbanics R; Szebeni J; Hunter AC; Mitragotri S; Mollnes TE; Moghimi SM Bypassing Adverse Injection Reactions to Nanoparticles through Shape Modification and Attachment to Erythrocytes. Nat. Nanotechnol 2017, 12, 589594. [PubMed: 28396605]

(18). Pelegri-O’Day EM; Lin EW; Maynard HD Therapeutic Protein-Polymer Conjugates: Advancing beyond PEGylation. J. Am. Chem. Soc 2014, 136, 14323-14332. [PubMed: 25216406]

(19). de la Rosa VR Poly(2-Oxazoline)s as Materials for Biomedical Applications. J. Mater. Sci.: Mater. Med 2014, 25, 1211-1225. [PubMed: 23975334]

(20). Koshkina O; Westmeier D; Lang T; Bantz C; Hahlbrock A; Wurth C; Resch-Genger U; Braun U; Thiermann R; Weise C; Eravci M; Mohr B; Schlaad H; Stauber RH; Docter D; Bertin A; Maskos M Tuning the Surface of Nanoparticles: Impact of Poly(2-Ethyl-2-Oxazoline) on Protein Adsorption in Serum and Cellular Uptake. Macromol. Biosci 2016, 16, 1287-1300. [PubMed: 27281039]

(21). Luxenhofer R; Schulz A; Roques C; Li S; Bronich TK; Batrakova EV; Jordan R; Kabanov AV Doubly Amphiphilic poly(2-Oxazoline)s as High-Capacity Delivery Systems for Hydrophobic Drugs. Biomaterials 2010, 31, 4972-4979. [PubMed: 20346493]

(22). Konradi R; Acikgoz C; Textor M Polyoxazolines for Nonfouling Surface Coatings-a Direct Comparison to the Gold Standard PEG. Macromol. Rapid Commun 2012, 33, 1663-1676.

(23). Mansfield ED; Sillence K; Hole P; Williams AC; Khutoryanskiy VV POZylation: A New Approach to Enhance Nanoparticle Diffusion through Mucosal Barriers. Nanoscale 2015, 7, 13671-13679. [PubMed: 26214263]

(24). Sedlacek O; Monnery BD; Filippov SK; Hoogenboom R; Hruby M Poly(2-Oxazoline)s-Are They More Advantageous for Biomedical Applications than Other Polymers? Macromol. Rapid Commun 2012, 33, 1648-1662. [PubMed: 23034926]

(25). Viegas TX; Bentley MD; Harris JM; Fang Z; Yoon K; Dizman B; Weimer R; Mero A; Pasut G; Veronese FM Polyoxazoline: Chemistry, Properties, and Applications in Drug Delivery. Bioconjugate Chem 2011, 22, 976-986.

(26). Konradi R; Pidhatika B; Muhlebach A; Textor M Poly-2-Methyl-2-Oxazoline: A Peptide-like Polymer for Protein-Repellent Surfaces. Langmuir 2008, 24, 613-616. [PubMed: 18179272]

(27). Zalipsky S; Hansen CB; Oaks JM; Allen TM Evaluation of Blood Clearance Rates and Biodistribution of poly(2-Oxazoline)-Grafted Liposomes. J. Pharm. Sci 1996, 85, 133-137. [PubMed: 8683436]

(28). He Z; Miao L; Jordan R; S-Manickam D; Luxenhofer R; Kabanov AV A Low Protein Binding Cationic Poly(2-Oxazoline) as Non-Viral Vector. Macromol. Biosci 2015, 15, 1004-1020. [PubMed: 25846127]

(29). Zhang N; Pompe T; Amin I; Luxenhofer R; Werner C; Jordan R Tailored poly(2-Oxazoline) Polymer Brushes to Control Protein Adsorption and Cell Adhesion. Macromol. Biosci 2012, 12, 926-936. [PubMed: 22610725]

(30). Koshkina O; Lang T; Thiermann R; Docter D; Stauber RH; Secker C; Schlaad H; Weidner S; Mohr B; Maskos M; Bertin A Temperature-Triggered Protein Adsorption on Polymer-Coated Nanoparticles in Serum. Langmuir 2015, 31, 8873-8881. [PubMed: 26209261]

(31). Woodle MC; Engbers CM; Zalipsky S New Amphipatic Polymer-Lipid Conjugates Forming Long-Circulating Reticuloendothelial System-Evading Liposomes. Bioconjugate Chem 1994, 5, 493-496.

(32). Bludau H; Czapar AE; Pitek AS; Shukla S; Jordan R; Steinmetz NF POxylation as an Alternative Stealth Coating for Biomedical Applications. Eur. Polym. J 2017, 88, 679-688. [PubMed: 28713172]

(33). Banda NK; Mehta G; Chao Y; Wang G; Inturi S; Fossati-Jimack L; Botto M; Wu L; Moghimi SM; Simberg D Mechanisms of Complement Activation by Dextran-Coated Superparamagnetic Iron Oxide (SPIO) Nanoworms in Mouse versus Human Serum. Part. Fibre Toxicol 2014, 11, 62-64. [PubMed: 25487196]

(34). Rio-Echevarria IM; Selvestrel F; Segat D; Guarino G; Tavano R; Causin V; Reddi E; Papini E; Mancin F Highly PEGylated Silica Nanoparticles: "ready to Use"” Stealth Functional Nanocarriers. J. Mater. Chem 2010, 20, 2780-2787. 
(35). Wibroe PP; Ahmadvand D; Oghabian MA; Yaghmur A; Moghimi SM An Integrated Assessment of Morphology, Size, and Complement Activation of the PEGylated Liposomal Doxorubicin Products Doxil®, Caelyx®, DOXOrubicin, and SinaDoxosome. J. Controlled Release 2016, 221, 1-8.

(36). Sahu A; Lambris JD Structure and Biology of Complement Protein C3, a Connecting Link between Innate and Acquired Immunity. Immunol. Rev 2001, 180, 35-48. [PubMed: 11414361]

(37). Merle NS; Church SE; Fremeaux-Bacchi V; Roumenina LT Complement System Part I Molecular Mechanisms of Activation and Regulation. Front. Immunol 2015, 6, 262. [PubMed: 26082779]

(38). Matsushita M; Endo Y; Fujita T Structural and Functional Overview of the Lectin Complement Pathway: Its Molecular Basis and Physiological Implication. Arch. Immunol. Ther. Exp 2013, 61, 273-283.

(39). Wallis R Structural and Functional Aspects of Complement Activation by Mannose-Binding Protein. Immunobiology 2002, 205, 433-445. [PubMed: 12396005]

(40). Petersen SV; Thiel S; Jensen L; Vorup-Jensen T; Koch C; Jensenius JC Control of the Classical and the MBL Pathway of Complement Activation. Mol. Immunol 2000, 37, 803-811. [PubMed: 11257302]

(41). Martin M; Leffler J; Blom AM Annexin A2 and A5 Serve as New Ligands for C1q on Apoptotic Cells. J. Biol. Chem 2012, 287, 33733-33744. [PubMed: 22879587]

(42). Païdassi H; Tacnet-Delorme P; Garlatti V; Darnault C; Ghebrehiwet B; Gaboriaud C; Arlaud GJ; Frachet P C1q Binds Phosphatidylserine and Likely Acts as a Multiligand-Bridging Molecule in Apoptotic Cell Recognition. J. Immunol 2008, 180, 2329-2338. [PubMed: 18250442]

(43). Bradley AJ; Brooks DE; Norris-Jones R; Devine DV C1q Binding to Liposomes Is Surface Charge Dependent and Is Inhibited by Peptides Consisting of Residues 14-26 of the Human C1qA Chain in a Sequence Independent Manner. Biochim. Biophys. Acta, Biomembr 1999, 1418, 19-30.

(44). Kovacsovics T; Tschopp J; Kress A; Isliker H Antibody-Independent Activation of C1, the First Component of Complement, by Cardiolipin. J. Immunol 1985, 135, 2695-2700. [PubMed: 4031497]

(45). Schottler S; Becker G; Winzen S; Steinbach T; Mohr K; Landfester K; Mailander V; Wurm FR Protein Adsorption Is Required for Stealth Effect of Poly(ethylene Glycol)- and Poly(phosphoester)-Coated Nanocarriers. Nat. Nanotechnol 2016, 11, 372-377. [PubMed: 26878141]

(46). Choi NH; Nakano Y; Tobe T; Mazda T; Tomita M Incorporation of SP-40,40 into the Soluble Membrane Attack Complex (SMAC, SC5b-9) of Complement. Int. Immunol 1990, 2, 413-417. [PubMed: 2150757]

(47). Bhakdi S; Käflein R; Halstensen TS; Hugo F; Preissner KT; Mollnes TE. Complement S-Protein (Vitronectin) Is Associated with Cytolytic Membrane-Bound C5b-9 Complexes. Clin. Exp. Immunol 1988, 74, 459-464. [PubMed: 2466593]

(48). Tschopp J; Chonn A; Hertig S; French LE Clusterin, the Human Apolipoprotein and Complement Inhibitor, Binds to Complement C7, C8 Beta, and the B Domain of C9. J. Immunol 1993, 151, 2159-2165. [PubMed: 8345200]

(49). Hattori R; Hamilton KK; McEver RP; Sims PJ Complement Proteins C5b-9 Induce Secretion of High Molecular Weight Multimers of Endothelial von Willebrand Factor and Translocation of Granule Membrane Protein GMP-140 to the Cell Surface. J. Biol. Chem 1989, 264, 9053-9060. [PubMed: 2470750]

(50). Jenne DE; Lowin B; Peitsch MC; Böttcher A; Schmitz G; Tschopp J Clusterin (Complement Lysis Inhibitor) Forms a High Density Lipoprotein Complex with Apolipoprotein A-I in Human Plasma. J. Biol. Chem 1991, 266, 11030-11036. [PubMed: 1904058]

(51). Gabizon A; Papahadjopoulos D Liposome Formulations with Prolonged Circulation Time in Blood and Enhanced Uptake by Tumors. Proc. Natl. Acad. Sci. U. S. A 1988, 85, 6949-6953 [PubMed: 3413128]

(52). Liu D; Song YK; Liu F Antibody Dependent, Complement Mediated Liver Uptake of Liposomes Containing GM1. Pharm. Res 1995, 12, 1775-1780. [PubMed: 8592685] 
(53). Moghimi SM Nanomedicine Safety in Preclinical and Clinical Development: Focus on Idiosyncratic Injection/infusion Reactions. Drug Discovery Today 2017, DOI: 10.1016/j.drudis. 2017.11.006.

(54). Fedeli C; Segat D; Tavano R; De Franceschi G; de Laureto PP; Lubian E; Selvestrel F; Mancin F; Papini E Variations of the Corona HDL:albumin Ratio Determine Distinct Effects of Amorphous $\mathrm{SiO} 2$ Nanoparticles on Monocytes and Macrophages in Serum Nanomedicine (London, U. K.) 2014, 9, 2481-2497. [PubMed: 24661258]

(55). Segat D; Tavano R; Donini M; Selvestrel F; Rio-Echevarria I; Rojnik M; Kocbek P; Kos J; Iratni S; Sheglmann D; Mancin F; Dusi S; Papini E Proinflammatory Effects of Bare and PEGylated ORMOSIL-, PLGA- and SUV-NPs on Monocytes and PMNs and Their Modulation by F-MLP Nanomedicine (London, U. K.) 2011, 6, 1027-1046. [PubMed: 21644818]

(56). Stanley ER Murine Bone Marrow-Derived Macrophages. Methods Mol. Biol 1997, 75, 301-304. [PubMed: 9276279]

(57). Fedeli C; Segat D; Tavano R; Bubacco L; De Franceschi G; de Laureto PP; Lubian E; Selvestrel F; Mancin F; Papini E The Functional Dissection of the Plasma Corona of SiO(2)-NPs Spots Histidine Rich Glycoprotein as a Major Player Able to Hamper Nanoparticle Capture by Macrophages. Nanoscale 2015, 7, 17710-17728. [PubMed: 26451907]

(58). Schwartz JT; Barker JH; Long ME; Kaufman J; McCracken J; Allen LA Natural IgM Mediates Complement-Dependent Uptake of Francisella Tularensis by Human Neutrophils via Complement Receptors 1 and 3 in Nonimmune Serum. J. Immunol 2012, 189, 3064-3077. [PubMed: 22888138]

(59). Lachmann PJ Preparing Serum for Functional Complement Assays. J. Immunol. Methods 2010, 352, 195-197. [PubMed: 19909755]

(60). Gerotto C; Franchin C; Arrigoni G; Morosinotto T In Vivo Identification of Photosystem II Light Harvesting Complexes Interacting with PHOTOSYSTEM II SUBUNIT S. Plant Physiol 2015, 168, 1747-1761. [PubMed: 26069151]

(61). Cox J; Mann M MaxQuant Enables High Peptide Identification Rates, Individualized P.p.b.Range Mass Accuracies and Proteome-Wide Protein Quantification. Nat. Biotechnol 2008, 26, 1367-1372. [PubMed: 19029910]

(62). Cox J; Neuhauser N; Michalski A; Scheltema RA; Olsen JV; Mann M Andromeda: A Peptide Search Engine Integrated into the MaxQuant Environment. J. Proteome Res 2011, 10, 17941805. [PubMed: 21254760]

(63). Wright JC; Collins MO; Yu L; Käll L; Brosch M; Choudhary JS Enhanced Peptide Identification by Electron Transfer Dissociation Using an Improved Mascot Percolator. Mol. Cell. Proteomics 2012, 11, 478-491. [PubMed: 22493177]

(64). Schwanhausser B; Busse D; Li N; Dittmar G; Schuchhardt J; Wolf J; Chen W; Selbach M Global Quantification of Mammalian Gene Expression Control. Nature 2011, 473, 337-342. [PubMed: 21593866]

(65). Kim ST; Kim SG; Hwang DH; Kang SY; Kim HJ; Lee BH; Lee JJ; Kang KY Proteomic Analysis of Pathogen-Responsive Proteins from Rice Leaves Induced by Rice Blast Fungus, Magnaporthe Grisea. Proteomics 2004, 4, 3569-3578. [PubMed: 15478215]

(66). Andersen AJ; Windschiegl B; Ilbasmis-Tamer S; Degim IT; Hunter AC; Andresen TL; Moghimi SM Complement Activation by PEG-Functionalized Multi-Walled Carbon Nanotubes Is Independent of PEG Molecular Mass and Surface Density. Nanomedicine 2013, 9, 469-473. [PubMed: 23434678] 


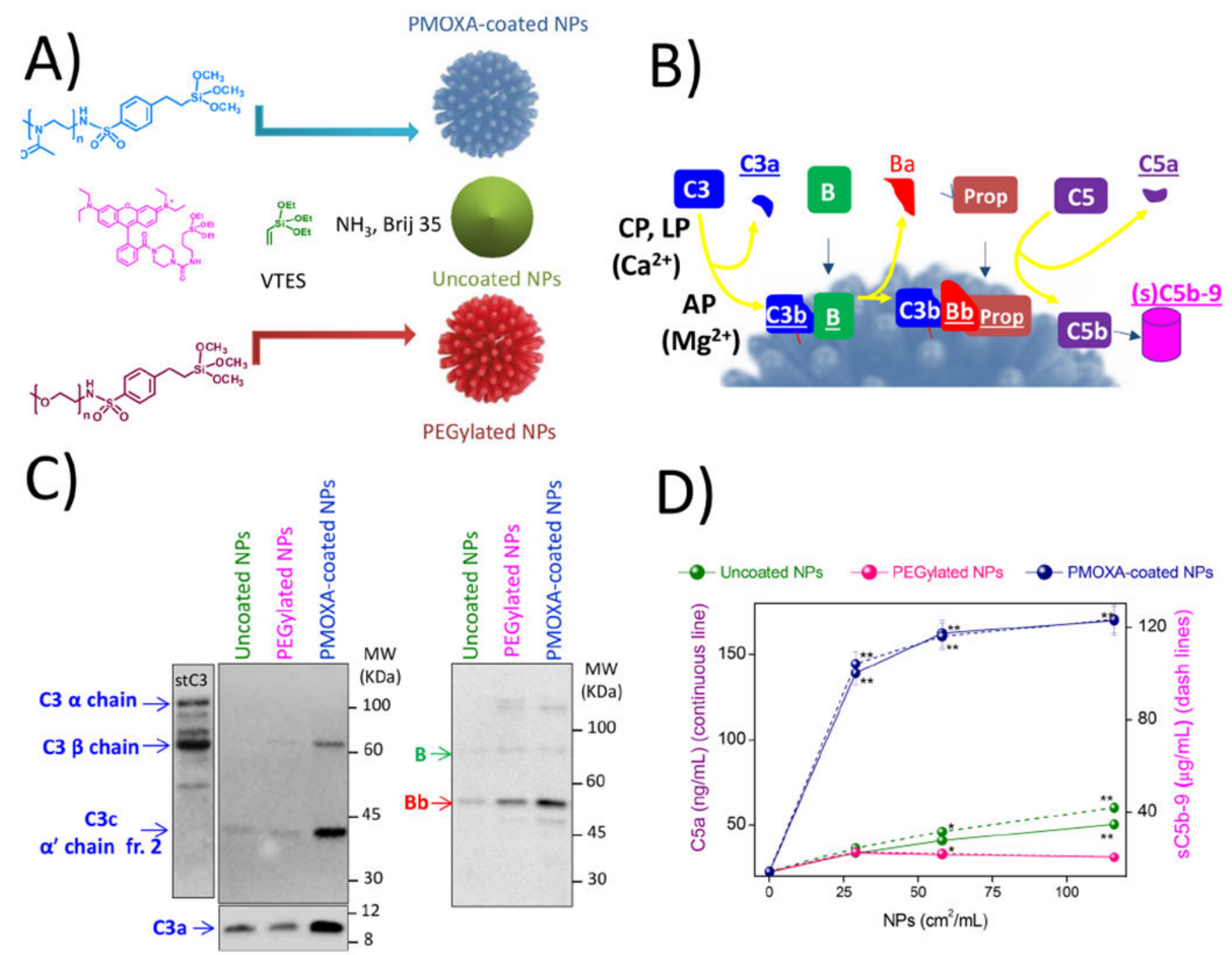

Figure 1.

Complement activation by engineered NPs in human serum. (A) Schematic representation of NP structure. (B) Simplified scheme of complement activation pathways (CP, classical pathway; LP, lectin pathway; AP, alternative pathway). The scheme depicts $\mathrm{C} 3$ conversion into $\mathrm{C} 3 \mathrm{~b}$ through assembly of pathway-dependent $\mathrm{C} 3$ convertases and generation of measurable complement activation products such as $\mathrm{C} 3 \mathrm{a}, \mathrm{Bb}, \mathrm{C} 5 \mathrm{a}$, and sC5b-9. (C) Western blot analysis of complement activation products by NPs. The panel shows detection of C3a $\left(M_{\mathrm{W}} \sim 9 \mathrm{kDa}\right)$ in the fluid phase and surface-bound C3 $a\left(M_{\mathrm{W}} \sim 110 \mathrm{kDa}\right), \mathrm{C} 3 \beta\left(M_{\mathrm{W}} \sim 70\right.$ $\mathrm{kDa}$ ) chains, C3c $a^{\prime}$ chain fragment 2 (a fragment of C $\left.3 \mathrm{~d}, M_{\mathrm{W}} \sim 39 \mathrm{kDa}\right)$, factor B $\left(M_{\mathrm{W}} \sim\right.$ $85 \mathrm{kDa})$, and $\mathrm{Bb}\left(M_{\mathrm{W}} \sim 55 \mathrm{kDa}\right)$ from washed NPs. StC3 represents purified human C3. (D) Determination of NP-mediated complement activation as a function of NP surface area by ELISA. Complement activation was monitored through measurements of fluid phase C5a and sC5b-9. Data are mean $\pm \mathrm{SE}(n=3)$. Statistical analyses were performed with student's $t$ test to calculate significance $(* p<0.05, * * p<0.01)$ compared with corresponding controls. Zymosan $(200 \mu \mathrm{g} / \mathrm{mL})$ was used as the positive control for monitoring complement activation, resulting in formation of $249 \mathrm{ng} / \mathrm{mL}$ serum of C5a and $35707 \mathrm{ng} / \mathrm{mL}$ serum of 
sC5b-9. The maximal effect of PMOXA NPs correspond to 67\% (C5a) and 35\% (sC5b-9) of the Zymosan activity. 

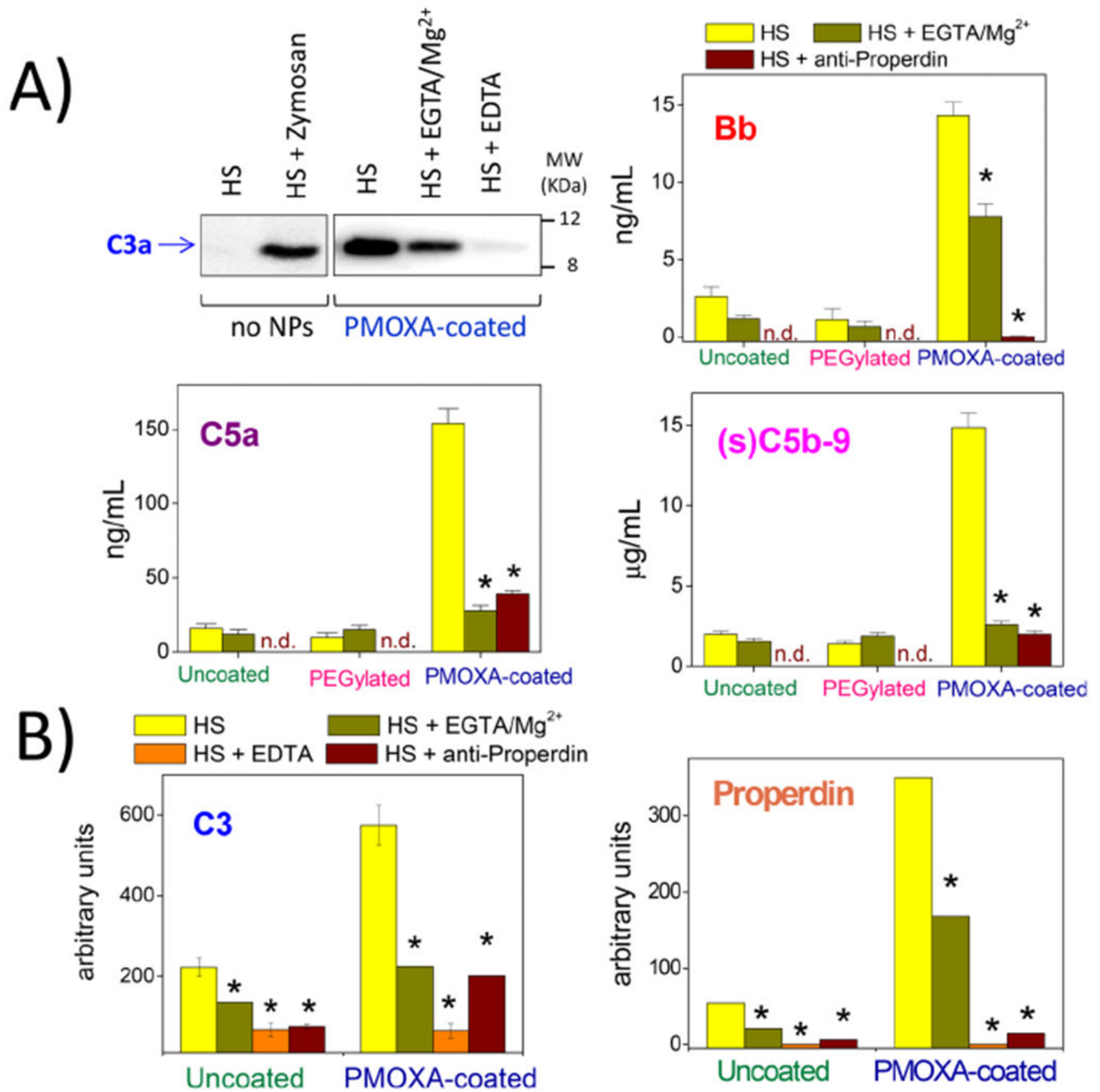

Figure 2.

Effect of divalent cation chelation and antiproperdin antibodies on complement activation by engineered NPs in HS. (A) Western blot representation (repeated three times) of C3a generation by PMOXA-coated NPs in normal HS and after serum treatment with chelating agents (top left panel). Control lanes include untreated HS (negative control) and HS incubated with Zymosan $\left(100 \mu \mathrm{g} / \mathrm{mL}\right.$; positive control). Other panels show NP $\left(119 \mathrm{~cm}^{2} /\right.$ $\mathrm{mL}$ )-mediated $\mathrm{C} 5 \mathrm{a}, \mathrm{Bb}$, and $\mathrm{sC} 5 \mathrm{~b}-9$ release (determined by ELISA) before and after serum treatment with either chelating agents or antiproperdin antibodies. Data are the mean $\pm \mathrm{SE}$ ( $n$ 
= 3). (B) Densitometric quantification (arbitrary units) of dot blot analysis of C3 and properdin binding to engineered NPs on incubation with untreated, chelated, and antiproperdin antibody-treated HS. Values are mean \pm SE $(n=3) ; *$ statistical significance ( $p$ $<0.05)$ compared with respective controls. 
A)

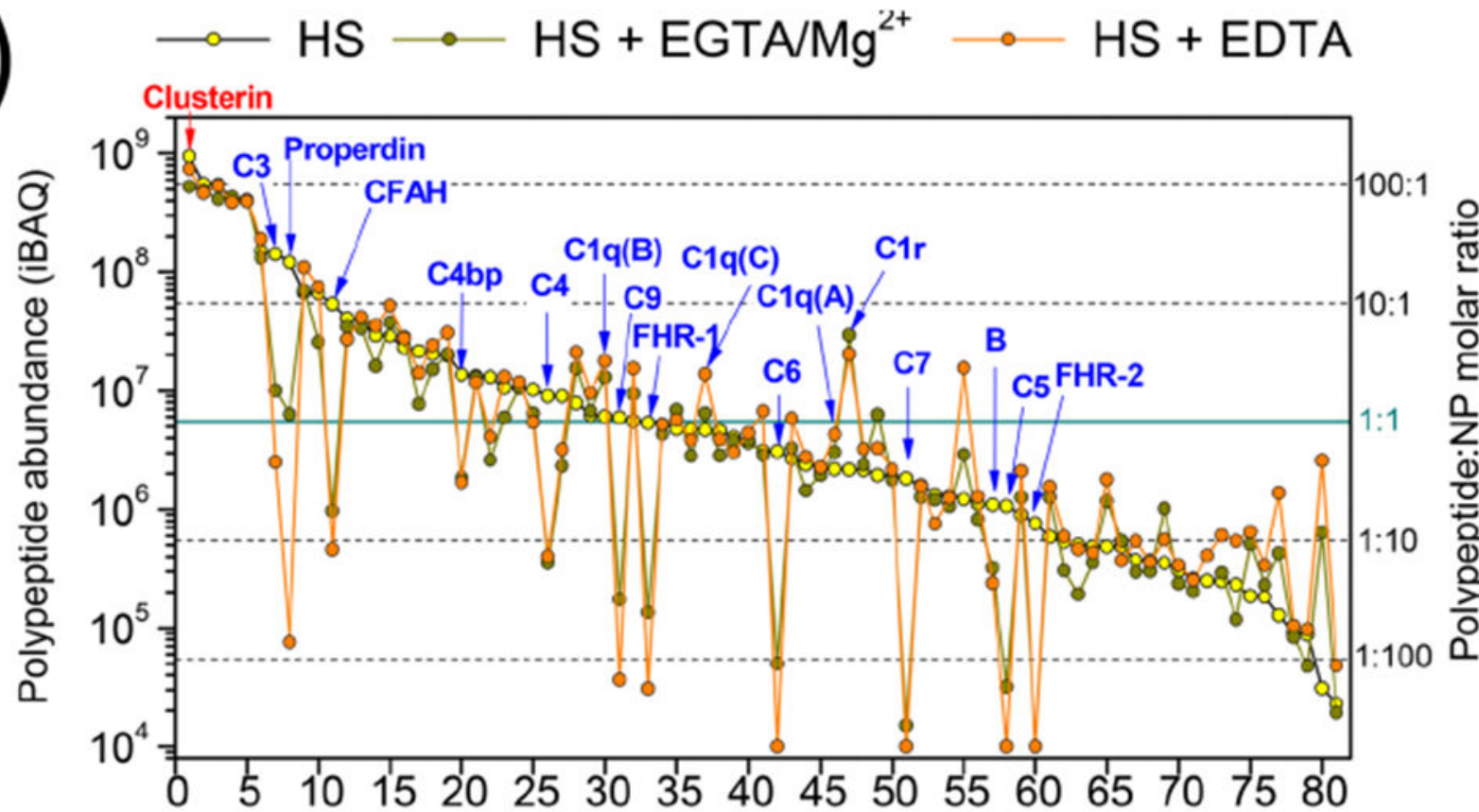

Polypeptides in order of abundance in control (no chelating agents)

B)

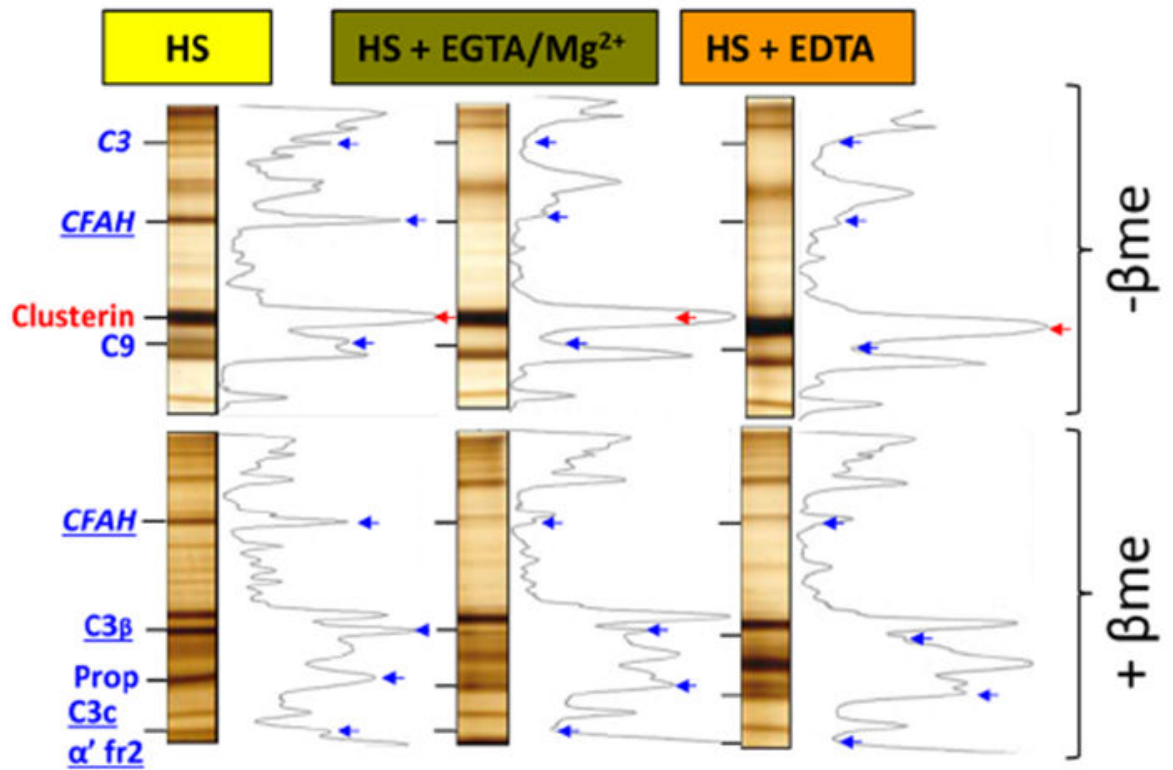

Figure 3.

Proteomics analysis of complement proteins on engineered NPs. (A) Shot-gun and label-free quantification of complement proteins from protein corona of PMOXA-coated NPs after incubation in untreated and chelated HS. The iBAQ values (left axis) of identified polypeptides were plotted in order of abundance in control samples. Right axis indicates approximate stoichiometry per NP for each polypeptide. Complement proteins are indicated by blue arrows. Clusterin is shown in red. (B) Mass spectrometry after SDS-PAGE, in-gel digestion, and densitometry. The representative panel shows the identification of major 
complement proteins and their fragments (in blue) in the corona of PMOXA-coated NPs (exemplified in the pictogram on the left). NP-bound proteins are highlighted by densitometry after nonreducing $(-\beta \mathrm{me})$ and reducing $(+\beta \mathrm{me})$ electrophoresis and silver staining. Peaks corresponding to complement proteins (and their fragments) are indicated by blue arrows. The clusterin band is indicated in red. 

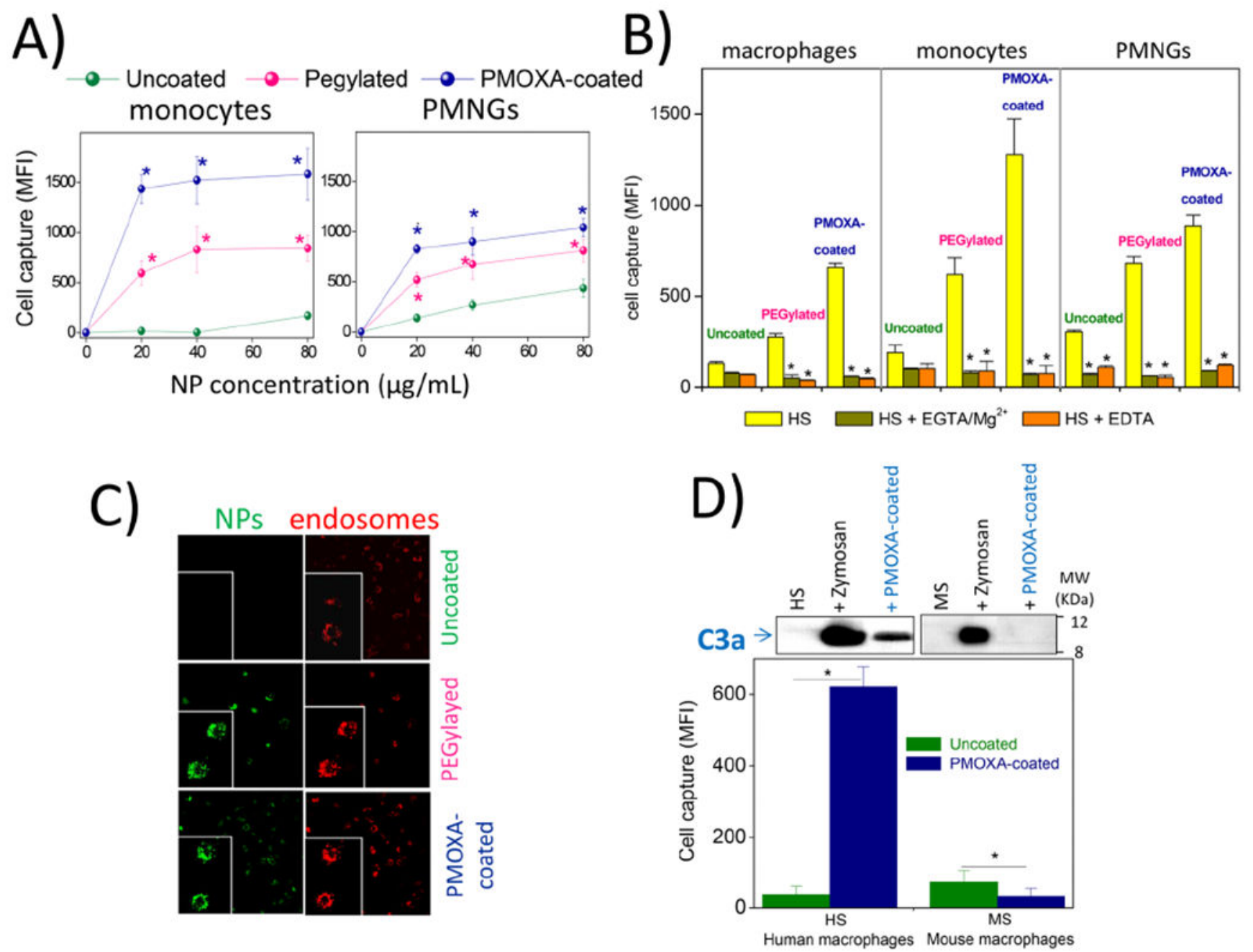

Figure 4.

Capture of PMOXA-coated NPs by human phagocytes. (A) Uncoated and polymer-coated NPs were treated with HS and incubated at designated concentrations with primary human blood monocytes and PMNGs. After being incubated for $3 \mathrm{~h}$ at $37^{\circ} \mathrm{C}$, cells were washed with PBS and their mean fluorescence intensity (MFI) was measured by FACS as a read out of NP-cell association (instrumental setting was constant to ensure cell-cell quantitative comparison). Data are mean $\pm \mathrm{SE}$ ( $n=3$; samples in triplicate in each experiments). (B) NP uptake by human macrophages and blood leukocytes following NP treatment in untreated or chelated HS. NP concentration was $80 \mu \mathrm{g} / \mathrm{mL}$ ( $n=4$; samples in duplicate in each experiments); *statistical significance ( $p<0.05$ ) compared with respective controls (HS). (C) Fluorescent microscopy images of NP internalization by human monocyte-derived macrophages. NP concentration was $80 \mu \mathrm{g} / \mathrm{mL}$. Green and red correspond to NPs and Lysotracker-labeled acidic endolysosomes, respectively. Insets are magnified views of selected fields. (D) Species difference in PMOXA-coated NP-mediated complement activation and macrophage uptake. PMOXA-coated NPs were incubated for $30 \mathrm{~min}$ at $37{ }^{\circ} \mathrm{C}$ with either $75 \%$ (v/v) human serum or mouse serum. Fluid-phase C3a was measured by Western blot (top panels), indicating NP-mediated complement activation. Negative controls 
(sera with no NPs) and positive controls (Zymosan-treated sera) were also run and analyzed as indicated. After sera incubation, NPs were diluted 10-fold in RPMI medium and further incubated for $3 \mathrm{~h}$ at $37{ }^{\circ} \mathrm{C}$ with human or mouse primary macrophages (as indicated).

Uncoated NPs were also used in this assay for comparison. NP capture was estimated by FACS and expressed as MFI. Data are the mean $\pm \operatorname{SE}\left(n=3\right.$, samples run in triplicate); ${ }^{*} p<$ 0.05 . 
A)
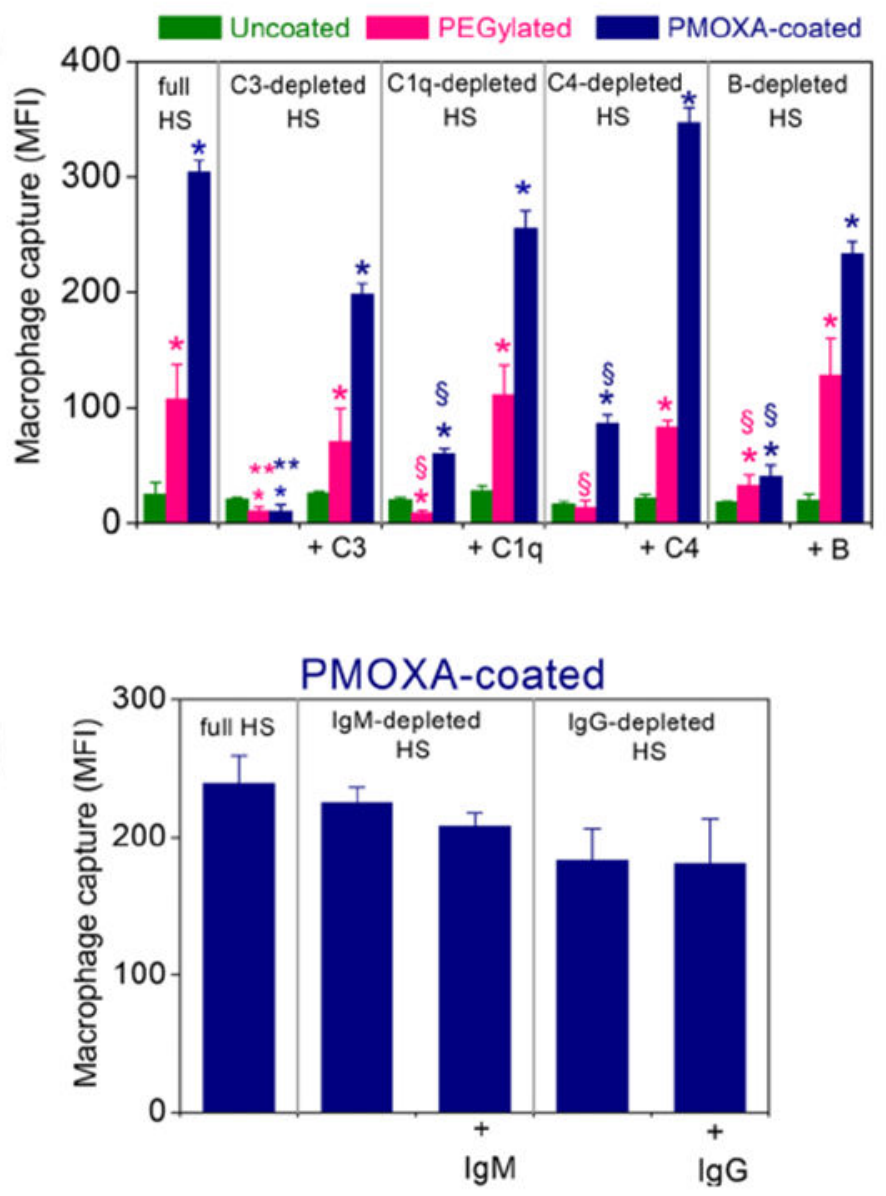

Figure 5.
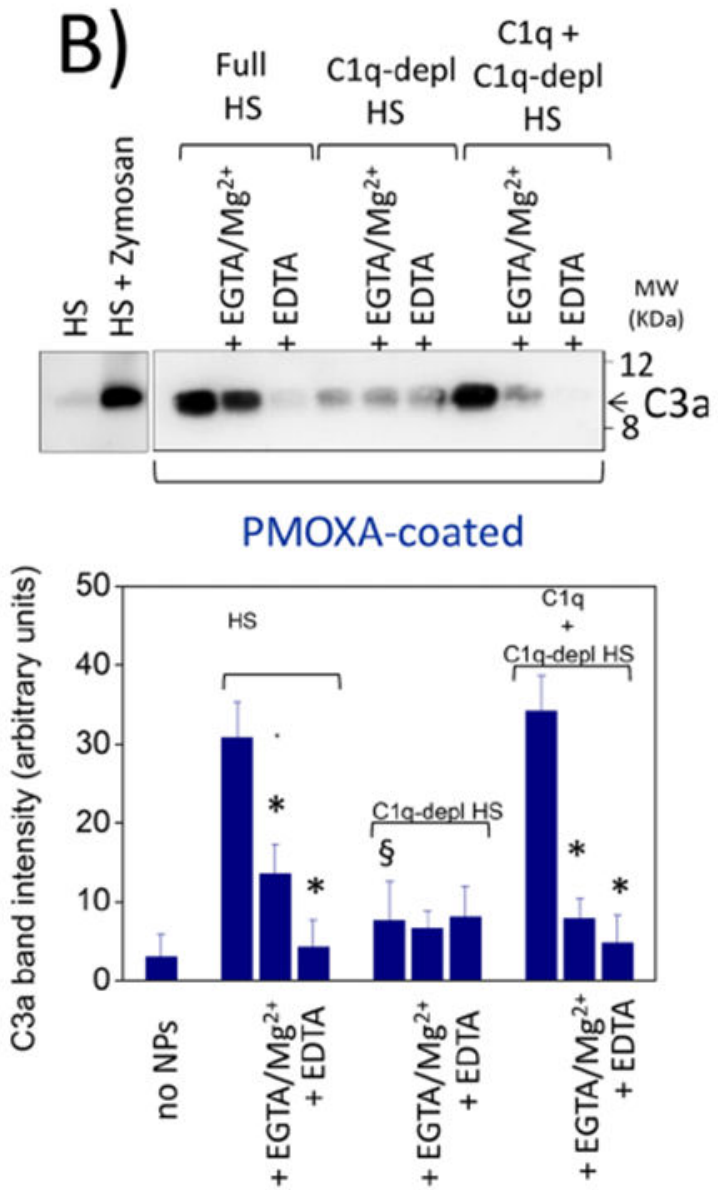

Mechanism of complement-mediated PMOXA-coated NP macrophage capture. (A)

Macrophage uptake $\left(3 \mathrm{~h}, 37^{\circ} \mathrm{C}\right)$ of uncoated and polymer-coated NPs treated with control HS (full HS) or sera depleted of selected complement proteins (C1q, C3, C4, and factor B). Uptake was further monitored on restoration of the depleted factor; *statistical significance $(p<0.05)$ compared with corresponding uncoated NPs; $\S_{\text {statistical significance }(p<0.05)}$ compared with corresponding incubations in complement factor-depleted and complement factor-restored sera. (B) PMOXA-coated NPs were treated as in (A) with control HS (full HS), C1q-depleted HS, and C1q-depleted HS plus purified C1q $(100 \mu \mathrm{g} / \mathrm{mL})$ for $30 \mathrm{~min}$ at $37{ }^{\circ} \mathrm{C}$ in the absence or the presence of EGTA/ $\mathrm{Mg}^{2+}$ or EDTA, as indicated. C3a was then measured in the incubation media by Western blot (a representative blot is shown in the top panel, whereas densitometric evaluation is depicted in the bottom panel); *statistical significance $(p<0.05)$ compared with HS in each condition; $\S_{\text {statistical significance ( } p<}$ 0.05) compared with C1q-depleted HS serum as well as with C1q restoration. (C) Efficacy of PMOXA-coated NP uptake by macrophages after incubation with normal HS (full HS) and with the same HS after IgM or IgG depletion. Purified autologous IgM and $\operatorname{IgG}$ were added to the respective depleted sera for comparison. Macrophage uptake was measured as mean fluorescent intensity (mean $\pm \mathrm{SE}, n=3$, incubations in duplicate). Differences were not statistically significant $(p>0.05)$. 

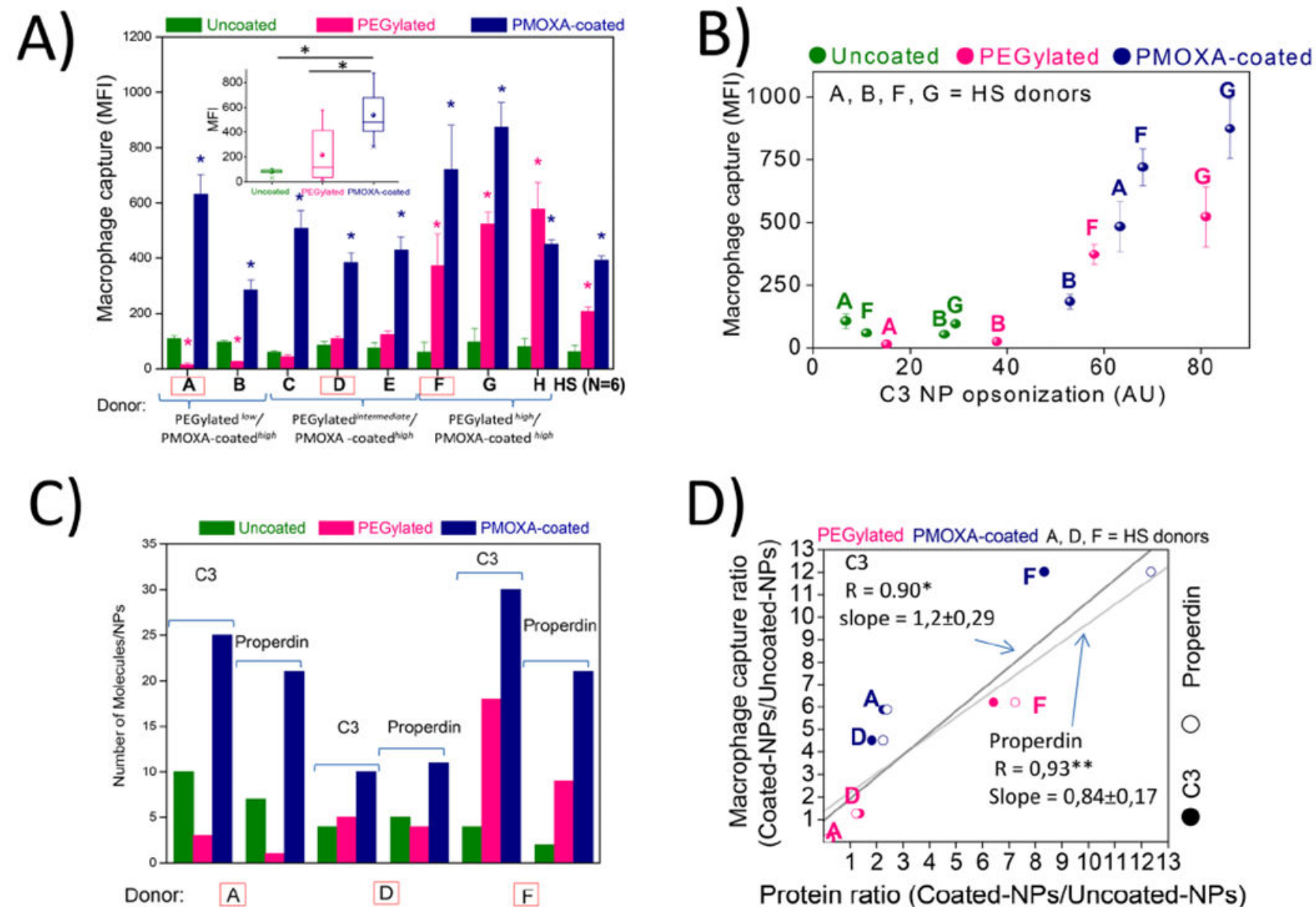

Protein ratio (Coated-NPs/Uncoated-NPs)

Figure 6.

Interindividual variability of HS on NP capture by macrophages and complement protein association. (A) Capture intensity of uncoated and polymer-coated NPs ( $80 \mu \mathrm{g} / \mathrm{mL})$ by human macrophages was measured by FACS after $3 \mathrm{~h}$ incubation at $37^{\circ} \mathrm{C}$. NPs were previously incubated with HS obtained from eight different donors $(\mathrm{A}-\mathrm{H})$ or with an independent commercially available pooled HS (CompTech, HS). The results are mean \pm SE ( $n=5$; duplicate incubations); *statistical significance compared with uncoated NPs in the same HS sample $(p<0.05)$. The inset represents the data from different donors as a whisker plot (bold symbol = mean; box $= \pm \mathrm{SE}$; whiskers $=$ max and min values) to show the general trend and the statistical variability $(* p<0.05)$. HS was ranked in three groups based on their efficacy to mediate PEGylated NP capture compared with uncoated NPs: PEG ${ }^{\text {low }}$ (PEGylated NPs capture statistically lower compared with uncoated NPs); PEG ${ }^{\text {intermediate }}$ (PEGylated NPs capture statistically not different from uncoated NPs); PEG ${ }^{\text {high }}$ (PEGylated NPs capture statistically higher than that of uncoated NPs). The red-boxed HS donors represent these three categories and were used for shot-gun proteomics. (B) Comparison of macrophage capturing efficacy of NPs after preincubation with HS from four donors (A, B, F, and G), measured by FACS after $3 \mathrm{~h}$ of incubation and represented as MFI (mean $\pm \mathrm{SE} ; n$ $=4$, samples in duplicate). The quantity of $\beta$ me-released corona $\mathrm{C} 3 \beta$ subunit (arbitrary units) was determined by densitometry following SDS-PAGE. (C) Stoichiometry of C3 and 
properdin based on IBAQ analysis following NP incubation with HS from the indicated donors and shot-gun proteomics. (D) Macrophage capture efficacies of polymer-coated NPs preincubated in sera of three donors (A, D, and F) were normalized to that of uncoated NPs one (macrophage capture ratio) and plotted against the amounts of $\mathrm{C} 3$ and properdin [estimated from the intensity parameter after shot-gun analysis, as well normalized to uncoated NPs values (protein ratio)]. Pearson correlation index $(R)$ and the slope $\pm \mathrm{SE}$ of the linear regression interpolation for both proteins are indicated $(* p<0.05 ; * *<0.01)$. 
Table 1.

Binding Constants $\left(K_{\mathrm{d}}\right)$ and Maximal Binding Stoichiometry $\left(B_{\max }\right)$ of the Indicated Purified Human Purified Proteins to PMOXA-Coated NPs ${ }^{a}$

\begin{tabular}{lcc}
\hline species & $\boldsymbol{K}_{\mathbf{d}} \pm$ SE $(\mathbf{n M})$ & $\boldsymbol{B}_{\max }($ number/NP) \\
\hline C1q & $11 \pm 1$ & $12 \pm 1$ \\
IgG & $1671 \pm 224$ & $48 \pm 4$ \\
HDL & $612 \pm 344$ & $226 \pm 58$ \\
\hline
\end{tabular}

${ }^{a} K_{\mathrm{d}}$ was calculated by nonlinear fitting, based on free protein determination in the presence of PMOXA-coated NPs at equilibrium (C1q and HDL) or on NP-recovered protein after washings $(\operatorname{IgG})$. Values are the mean $\pm \mathrm{SE}(n=3$; samples run in triplicate). 